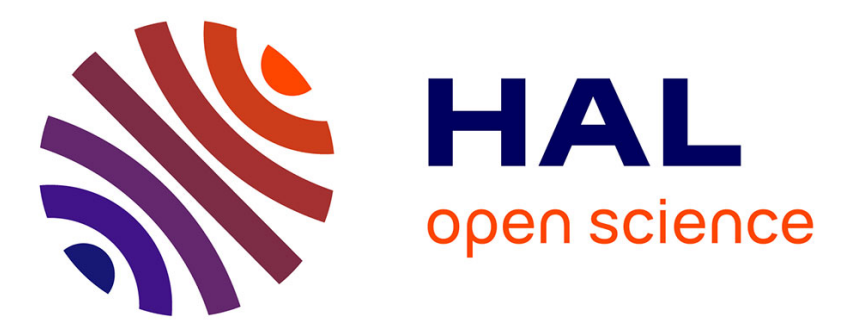

\title{
Reactivity of particulate element concentrations: apportionment assessment of suspended particulate matter sources in the Upper Rhône River, France
}

A. Dabrin, C. Bégorre, M. Bretier, V. Dugué, M. Masson, C. Le Bescond, J. Le Coz, M. Coquery

\section{To cite this version:}

A. Dabrin, C. Bégorre, M. Bretier, V. Dugué, M. Masson, et al.. Reactivity of particulate element concentrations: apportionment assessment of suspended particulate matter sources in the Upper Rhône River, France. Journal of Soils and Sediments, 2021, 21 (2), pp.1256-1274. 10.1007/s11368-020-028560 . hal-03487104

\author{
HAL Id: hal-03487104 \\ https://hal.inrae.fr/hal-03487104
}

Submitted on 17 Dec 2021

HAL is a multi-disciplinary open access archive for the deposit and dissemination of scientific research documents, whether they are published or not. The documents may come from teaching and research institutions in France or abroad, or from public or private research centers.
L'archive ouverte pluridisciplinaire HAL, est destinée au dépôt et à la diffusion de documents scientifiques de niveau recherche, publiés ou non, émanant des établissements d'enseignement et de recherche français ou étrangers, des laboratoires publics ou privés. 


\title{
Reactivity of particulate element concentrations: apportionment assessment of suspended particulate matter sources in the Upper Rhône River, France
}

\author{
A. Dabrin ${ }^{1}$ (D) $\cdot$ C. Bégorre ${ }^{1} \cdot$ M. Bretier ${ }^{1} \cdot$ V. Dugué ${ }^{1} \cdot$ M. Masson ${ }^{1} \cdot$ C. Le Bescond ${ }^{1} \cdot{\text { J. Le } \text { Coz }^{1} \cdot \text { M. Coquery }}^{1}$
}

Received: 7 November 2019 / Accepted: 2 December 2020 / Published online: 7 January 2021

(C) The Author(s), under exclusive licence to Springer-Verlag GmbH, DE part of Springer Nature 2021

\begin{abstract}
Purpose Suspended particulate matter (SPM) transport through rivers is a major vector of nutrients and pollutants to continental shelf areas. To develop efficient sediment management strategies, there is a need to obtain quantitative information on SPM sources. For many years, the geochemical properties of SPM have been commonly used as tracers to identify sediment sources. In large watersheds, with numerous sources, the expected alteration of tracers during their transport requires that their reactivity be taken into account.

Materials and methods To overcome this issue, we tested the use of major and trace element signatures in the residual fraction of SPM, using two different extraction methods. This original fingerprinting approach was applied to the Upper Rhône River basin $\left(\sim 20,000 \mathrm{~km}^{2}\right)$ in order to assess the respective SPM contributions of its main five tributaries (Arve, Ain, Fier, Guiers, and Bourbre Rivers) for contrasted hydrological conditions (base flow periods, flood events and dam flushing). By incorporating element concentrations previously corrected from particle size distribution in a mixing model coupled to Monte Carlo simulations, we estimated the associated uncertainties of the SPM contributions from each tributary. The relative SPM contributions obtained using this fingerprinting approach were compared with those calculated with a 1-D hydro-sedimentary model.

Results and discussion The use of element concentrations, such as $\mathrm{Zn}, \mathrm{P}, \mathrm{Cu}, \mathrm{Pb}, \mathrm{Mn}$, or $\mathrm{Sr}$, in the total fraction of SPM as conservative fingerprinting properties was not suitable, since they are mainly bound ( $>50 \%)$ to reactive carrier phases. By using $\mathrm{Ba}, \mathrm{Ni}, \mathrm{Fe}, \mathrm{Mg}, \mathrm{Cu}, \mathrm{Sr}$, and $\mathrm{V}$ concentrations in the SPM residual fraction, the apportionment modeling of SPM sources was successfully assessed. The fingerprinting approach showed that, in base flow conditions, SPM originated mainly from the Arve River. During dam flushing event, the fingerprinting approach consistently estimated that re-suspended sediments came from the Arve River, while the 1-D hydro-sedimentary model estimated a proportion of re-suspended sediment originating within the Rhône River.

Conclusions This original fingerprinting approach highlighted the relevance of using geochemical properties in the non-reactive fraction of SPM in order to obtain reliable information on spatial sources of SPM in a large river basin. This methodology opens up promising perspectives to better track SPM sources in highly reactive environments such as estuaries/delta or in historical sediment archives.
\end{abstract}

Keywords Fingerprinting $\cdot$ SPM fluxes $\cdot$ Trace metals $\cdot$ Sediment $\cdot$ Hydro-sedimentary model $\cdot$ Uncertainties

Responsible editor: Alexander Koiter

A. Dabrin

aymeric.dabrin@inrae.fr

1 INRAE, UR RiverLy, 5 Rue de la Doua CS 20244, Villeurbanne F-69625, France

\section{Introduction}

Natural processes such as soil weathering and erosion strongly control suspended particulate matter (SPM) inputs to rivers (Koiter et al. 2013). These particles are essential for aquatic ecosystems as they control the transport of nutrients, essential elements, and organic matter (House and Warwick 1999; Collins et al. 2005). However, excessive inputs of SPM can 
ultimately degrade water quality. Indeed, several contaminants such as trace metals, polychlorinated biphenyls, or polycyclic aromatic hydrocarbons can be bound to particles characterized by large surface specific area and high surface reactivity, which makes SPM a major source of contaminant fluxes in surface freshwaters (Heemken et al. 2000). Gellis and Walling (2011) showed how vital it is to combine source estimation and SPM budget approaches in order to provide resource managers with the necessary information and support for reducing SPM and associated contaminant fluxes. Source estimation approaches can quantify the relative importance of potential sources of SPM, while SPM budget approaches provide information on the magnitude of the SPM fluxes and the links between SPM sources and sinks. Since the estimation of SPM sources through monitoring networks is expensive and requires ongoing maintenance, several fingerprinting methods have been developed in the past 40 years to obtain quantitative information on spatial distribution (e.g. individual tributaries, geological zones) and type (e.g. surface soils and channel banks) of SPM sources (e.g. Walling 2013). These methods are based on the fact that SPM from each sub-catchment are characterized by distinct geophysical and geochemical and biochemical properties, which could be used to determine the relative proportion of SPM from each potential upstream source (Walling et al. 1999). As no single property can reliably distinguish various sources of SPM (Collins et al. 1997), various physico-chemical characteristics of SPM have been used to assess their origin, such as major elements and trace metals (Collins et al. 2012), rare earth elements (Kimoto et al. 2006), mineralogy and magnetism (Rotman et al. 2008), radionuclides (Zebracki et al. 2015), color properties (MartínezCarreras et al. 2010; Legout et al. 2013), isotopes (Mukundan et al. 2010), pollens (Brown et al. 2008), or biomarkers (Chen et al. 2016).

In order to determine SPM sources at any time and location within a watershed, the properties of SPM used in any fingerprinting method have to be conservative from the source area through the final area of sampling (Walling 2013). In some studies, a simple range test is incorporated into the data screening to confirm that the property values characterizing the target sediment fall within the range of the property values associated with the potential sources (Walling 2013). As mentioned by Walling (2013), enrichment and depletion effects caused by selective mobilization and transport, resulting in different grain size composition and organic matter content between target and source material samples, can be viewed as a form of non-conservative behavior. To overcome this problem, it is possible to remove organic matter from SPM by ashing and analyze only their mineral fraction (e.g. Wilkinson et al. 2013). However, this approach only corrects element concentrations that are strongly linked to particulate organic matter but fails to account for other reactive phases (e.g. carbonates). Laceby et al. (2017) reported in their review that to address particle size effect, fractionation of source sediment material (e.g. isolation of particle size fractions) or concentration correction (normalization) are often used in sediment fingerprinting studies. Some approaches simply restrict tracer analysis to specific particle size fractions of the SPM sample (e.g. below $63 \mu \mathrm{m}$ or $10 \mu \mathrm{m}$ ) (e.g. Fu et al. 2008), but these fine fractions are not necessarily representative of the total SPM load. In order to compare samples with similar particle size distribution or organic matter content, several approaches have been applied, such as using pre-sieved sediment or by applying correction factors (Motha et al. 2002). Gellis and Noé (2013) proposed to determine for each source if significant relationships exist between median values of the particle size distribution (D50) or total organic carbon (TOC) content and tracer concentrations. In case of a significant relationship, a correction factor could be applied to the tracer concentration. However, although particle size correction is widely applied, there are some documented limitations. For example, particle size corrections (i.e. positive linearity between particle size and tracer concentration) do not apply to all tracer properties or not equally to all tracers of SPM samples from different sources (Smith and Blake 2014).

In large-sized watersheds, the notion of conservative behavior of tracer properties is even more important than in small watersheds. Indeed, in addition to logistical difficulties to retrieve SPM over the entire system, tracer properties are subjected to intense modifications of physico-chemical conditions (e.g., ionic strength, $\mathrm{pH}$, and redox potential) during their transport, which will influence their partition between particulate and dissolved phases (Dabrin et al. 2009) by adsorbing, precipitating, or releasing them. Thus, tracer properties associated with highly reactive particulate carrier phases, such as Fe and Mn oxy-hydroxides, particulate organic matter, carbonates, and sulfides, may eventually be released in the dissolved phase, modifying the tracer signature in SPM or sediment. But, in the vast majority of fingerprinting studies, tracer properties, such as major and trace element concentrations, are commonly obtained after a total mineralization of SPM or sediment samples (e.g. triacid mineralization by using $\mathrm{HCl}, \mathrm{HNO}_{3}$ and $\mathrm{HF}$; Le Cloarec et al. 2011; Evrard et al. 2011). As this total extraction reflects the signature of the sum of the different carrier phases, this implies that the source signature inferred from total element concentrations may be modified according to the physico-chemical conditions that SPM will encounter during their transport. To overcome this issue, Maher et al. (2009) successfully used magnetic inclusions (protected within host silicate grains) to assess sediment sources in a tropical and marine context. In a similar way, Dabrin et al. (2014) proposed to use trace metal concentrations in the residual fraction of SPM, a fraction supposedly invariable. This approach was successfully applied to distinguish two main SPM sources on the French Atlantic coast. 
Validation of fingerprinting estimation also represents a big challenge. One of the most commonly used approaches is to compare model estimation with SPM and discharge monitoring data (e.g. Evrard et al. 2011). However, SPM sampling techniques represent some limitations in terms of practicalities and costs of deployment both spatially and temporally (Collins and Walling 2004). Moreover, SPM monitoring provides information on SPM fluxes but not directly on the origin of the remobilized sediment (Vale et al. 2016). Another way to address this problem is to prepare experimental mixtures in the laboratory with known proportions of SPM and their subsequent analysis (e.g. Franks and Rowan 2000). This validation by using real or virtual sediment mixtures (e.g. Palazon et al. 2015) is highly promising even if dealing with contrasted particle size distribution in source samples represents a challenge. A promising alternative is the use of a 1-D numerical model to simulate sediment transport (e.g. Launay et al. 2015; Maleki and Khan 2016). At the river network scale, most 1-D numerical models are able to simulate complex, multi-reach hydraulic networks, including artificial structures as well as bifurcations and confluences. Thus, these models are able to estimate the relative contributions of water discharge and SPM fluxes from each tributary at a downstream monitoring station, accounting for SPM propagation, deposition, and re-suspension.

In light of these findings, the objective of the present study was to assess the benefits of using major and trace element concentrations in the residual fraction of SPM rather than the total element concentrations, in order to fingerprint SPM sources in a large river catchment. The Upper Rhône, a large-sized watershed $\left(\sim 20,000 \mathrm{~km}^{2}\right)$ in France, including five main tributaries (the Ain, Arve, Bourbre, Guiers, and Fier Rivers), was used as a case study. Major and trace elements were analyzed in the total and in the residual fractions of SPM collected during contrasting hydrological conditions at the outlet of the main tributaries and at the outlet of the Upper Rhône River (Jons station) in order to characterize SPM sources. Then, source apportionment modeling was applied to SPM sampled for different hydrological conditions (base flow, floods, or dam flushing) at Jons station. Source apportionments inferred from fingerprinting approaches were compared to simulations obtained on the same sampling periods through 1-D hydro-sedimentary model computations.

\section{Material and methods}

\subsection{Study area and SPM sampling strategy}

The Rhône River is one of Europe's major rivers: at its outlet (Beaucaire station), its length is $812 \mathrm{~km}$, its mean discharge is $1690 \mathrm{~m}^{3} \mathrm{~s}^{-1}$, and its catchment area is $95,590 \mathrm{~km}^{2}$ (Fig. 1). It is the main source of water and SPM to the Mediterranean Sea
Fig. 1 Map of the Upper Rhône River (France), with the location of the sampling station at Jons and the 5 sampling stations on the main tributaries (Arve, Fier, Guiers, Ain, and Bourbre Rivers)

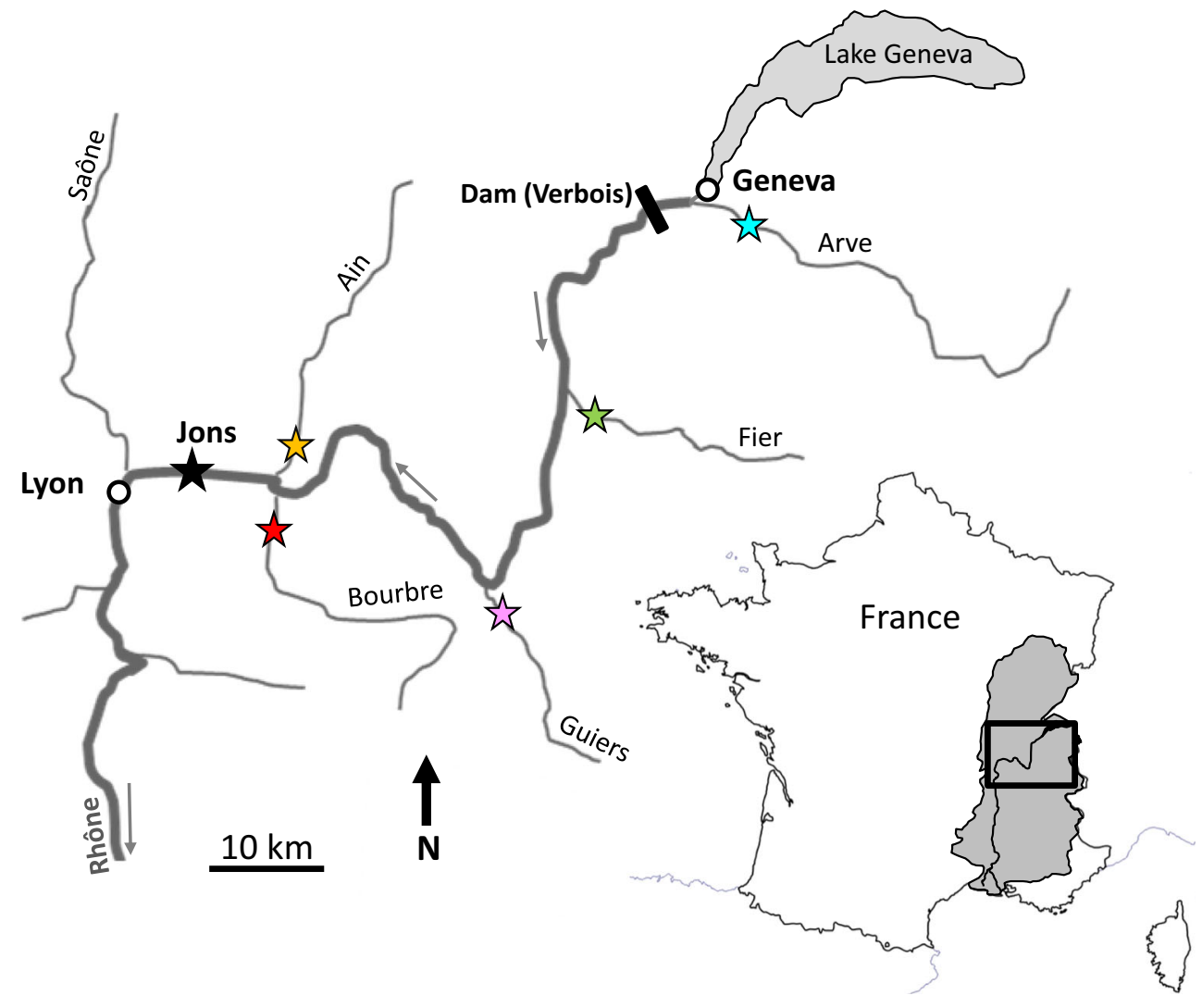


since the Aswan Dams were built across the Nile (Antonelli et al. 2008; Ollivier et al. 2011). Data on SPM sources are scarce and limited to the most southern tributaries of the Rhône catchment (Navratil et al. 2012; Zebracki et al. 2015). From Lake Geneva in Switzerland to the Mediterranean Sea, the Rhône River is strongly affected by industrial installations including factories, 21 hydroelectric plants, and four nuclear power plants. The SPM output of Lake Geneva is assumed to be negligible due to the large trapping capacity of the lake (Launay et al. 2019). At Jons station (JON, $20,000 \mathrm{~km}^{2}$ ), upstream of the city of Lyon, the Rhône receives water and SPM inputs from five main tributaries (Fig. 1, Table 1), namely, the Arve (ARV), the Fier (FIE), the Guiers (GUI), the Bourbre (BOU), and the Ain (AIN) Rivers. Monitoring stations (permanent or temporary) have been implemented at the outlet of each tributary since 2011 for the oldest, as part of the Rhône Sediment Observatory (OSR) program (Poulier et al. 2019). For each sampling station, all data of water discharge and SPM concentrations are available on the BDOH website (Thollet et al. 2018).

For each tributary, SPM samples $(9 \leq n \leq 16$, depending on the station) were collected between March 2011 and January 2015 by contrasting hydrological conditions (Table 2), i.e. during base flow periods and flood events (defined as peak water discharges with a return period greater than 2 years). Each tributary drains a large sub-basin that cannot be considered homogeneous in terms of land use, soil types, and geology. Therefore, it is important to collect samples under different hydrological conditions in order to take into account (i) as many different sources of SPM as possible within the subbasins and (ii) the idea of connectivity, whereas certain parts of the watersheds are only connected during high magnitude and low frequency events (Fryirs 2013). This sampling strategy allowed collecting samples for SPM concentrations ranging from 8.0 to $38 \mathrm{mg} \mathrm{L}^{-1}$ (AIN), 10 to $680 \mathrm{mg} \mathrm{L}^{-1}$ (ARV), 64 to $210 \mathrm{mg} \mathrm{L}^{-1}$ (BOU), 2.3 to $34 \mathrm{mg} \mathrm{L}^{-1}$ (FIE), and 8.0 to $269 \mathrm{mg} \mathrm{L}^{-1}$ (GUI). Moreover, 16 SPM samples were collected at the mixing station (Jons) during base flow periods, flood events, and dam flushing operations on the Verbois dam (June 2012, Lepage et al. 2020). Indeed, in 2012, the hydroelectric dam at Verbois, located $12 \mathrm{~km}$ downstream of the confluence of the Arve and Rhône Rivers (Fig. 1), was opened to avoid accidental flooding of the city of Geneva by flushing sediments from the Arve River accumulated since 2003. On the Rhône River at Jons station, SPM samples were collected for SPM concentrations ranging from 11 to $280 \mathrm{mg} \mathrm{L}^{-1}$, while during dam flushing operations SPM concentrations ranged from 160 to $660 \mathrm{mg} \mathrm{L}^{-1}$.

Suspended particles were retrieved by two complementary sampling methods (Table 2): time-integrative sediment particle traps (PT) or a continuous flow centrifuge (CFC; Westfalia KA 2-86-075-1978; $9700 \mathrm{rpm})$ as described by Masson et al. (2018). Comparisons between PT and CFC sampling methods conducted by Masson et al. (2018) have shown that no significant differences were found in PCB and Hg concentrations. We assume that such differences would also be negligible for metals. Two SPM samples were also retrieved using an automatic water sampler (Bühler 4011) at Jons station during the dam flushing event. The PTs were high-quality stainless steel boxes with three holes through the front and back faces allowing water to circulate inside. The PTs were typically installed at 50-100 cm below the water surface. Sampling with CFC was done by pumping water from the river into the centrifuge at a flow rate of $\sim 700-800 \mathrm{~L} \mathrm{~h}^{-1}$. The PTs and the CFC provided the amount of SPM (several grams of dry weight) necessary for the analysis of several parameters. Particles retrieved from the PT or obtained after centrifugation were homogenized in a glass bottle with a silicon spatula and were conditioned in an amber glass bottle for chemical analysis and in a polypropylene (PP) tube for grain size determination. Then, SPM collected in glass bottles were freeze-dried, ground, and stored at ambient temperature until chemical analysis. Suspended particulate matters collected in PP tubes were stored at $4{ }^{\circ} \mathrm{C}$ in the dark until particle size distribution analysis.

\subsection{Particle size distribution}

Volumetric particle size distribution of SPM was assessed by laser diffraction using a Cilas 1190 particle size analyzer according to the ISO 13320 standard method (AFNOR 2009b). A representative wet subsample was introduced into the

Table 1 Location of the sampling stations on the Upper Rhône River and characteristics of the 6 studied rivers and watersheds

\begin{tabular}{|c|c|c|c|c|c|c|c|c|}
\hline & River & $\begin{array}{l}\text { Mean annual } \\
\text { discharge } \\
\left(\mathrm{m}^{3} \mathrm{~s}^{-1}\right)\end{array}$ & $\begin{array}{l}\text { Mean annual SPM } \\
\text { concentrations } \\
\left(\mathrm{mg} \mathrm{L}^{-1}\right)\end{array}$ & $\begin{array}{l}\text { Sampling } \\
\text { station name }\end{array}$ & $\begin{array}{l}\text { Surface } \\
\text { area }\left(\mathrm{km}^{2}\right)\end{array}$ & $\begin{array}{l}\text { Distance from } \\
\text { Jons station } \\
(\mathrm{km})\end{array}$ & $\begin{array}{l}\text { Sampling station l } \\
\text { Lat./Long (WGS8 }\end{array}$ & cation \\
\hline ARV & Arve & 73 & 154 & Geneva, Bout du Monde & 2060 & 175 & $46^{\circ} 10^{\prime} 49.19^{\prime \prime} \mathrm{N}$ & $6^{\circ} 09^{\prime} 33.74^{\prime \prime} \mathrm{E}$ \\
\hline FIE & Fier & 41 & 35 & Motz & 1380 & 113 & $45^{\circ} 56^{\prime} 00.13^{\prime \prime} \mathrm{N}$ & $5^{\circ} 50^{\prime} 28.29^{\prime \prime} \mathrm{E}$ \\
\hline GUI & Guiers & 16 & 27 & Belmont-Tramonet & 609 & 77 & $45^{\circ} 34^{\prime} 23.28^{\prime \prime} \mathrm{N}$ & $5^{\circ} 39^{\prime} 04.09^{\prime \prime} \mathrm{E}$ \\
\hline $\mathrm{BOU}$ & Bourbre & 7.8 & 71 & Tignieux & 728 & 13 & $45^{\circ} 42^{\prime} 55.20^{\prime \prime} \mathrm{N}$ & $5^{\circ} 09^{\prime} 33.05^{\prime \prime} \mathrm{E}$ \\
\hline AIN & Ain & 123 & 5.4 & Pont de Chazay & 3600 & 27 & $45^{\circ} 49^{\prime} 55.11^{\prime \prime} \mathrm{N}$ & $5^{\circ} 13^{\prime} 44.46^{\prime \prime} \mathrm{E}$ \\
\hline JON & Rhône & 600 & 28 & Jons & 20,300 & - & $45^{\circ} 48^{\prime} 42.62^{\prime \prime} \mathrm{N}$ & $5^{\circ} 05^{\prime} 08.86^{\prime \prime} \mathrm{E}$ \\
\hline
\end{tabular}


Table 2 List of collected SPM samples, sampling methods, hydrological conditions, and SPM concentrations and particle size during base flow periods, flood events, and dam flushing operations. (ND: not determined)

\begin{tabular}{|c|c|c|c|c|c|c|c|}
\hline River & Sample & $\begin{array}{l}\text { SPM sampling } \\
\text { method }\end{array}$ & $\begin{array}{l}\text { Date/period } \\
\text { of sampling }\end{array}$ & $\begin{array}{l}\text { Hydrological } \\
\text { condition }\end{array}$ & $\begin{array}{l}\text { Mean discharge } \\
\left(\mathrm{m}^{3} \mathrm{~s}^{-1}\right)\end{array}$ & $\begin{array}{l}\text { Mean SPM } \\
\text { concentration } \\
\left(\mathrm{mg} \mathrm{L}^{-1}\right)\end{array}$ & $\begin{array}{l}\text { Particle size } \\
\text { D50 }(\mu \mathrm{m})\end{array}$ \\
\hline \multirow[t]{9}{*}{ Ain } & AIN_1 & Mobile centrifuge & $28 / 08 / 2012-25 / 09 / 2012$ & Base flow & 368 & ND & 13 \\
\hline & AIN_2 & Mobile centrifuge & $25 / 09 / 2012-23 / 10 / 2012$ & Flood & 688 & $\mathrm{ND}$ & 11 \\
\hline & AIN_3 & Mobile centrifuge & $23 / 10 / 2012-21 / 11 / 2012$ & Flood & 511 & ND & 7 \\
\hline & AIN_4 & Mobile centrifuge & $21 / 11 / 2012-28 / 01 / 2013$ & Flood & 679 & $\mathrm{ND}$ & 6 \\
\hline & AIN_5 & Mobile centrifuge & $08 / 12 / 2011$ & Flood & 721 & 83 & 5 \\
\hline & AIN_6 & Particle trap & $02 / 01 / 2012$ & Base flow & 72.9 & 8.4 & 20 \\
\hline & AIN_7 & Particle trap & $05 / 01 / 2012$ & Base flow & 158 & 23 & 18 \\
\hline & AIN_8 & Particle trap & $06 / 01 / 2012$ & Flood & 178 & 38 & 19 \\
\hline & AIN_9 & Particle trap & $11 / 11 / 2012$ & Flood & 269 & 34 & 27 \\
\hline \multirow[t]{10}{*}{ Arve } & ARV_1 & Mobile centrifuge & $14 / 03 / 2014-22 / 04 / 2014$ & Base flow & 17.4 & ND & ND \\
\hline & ARV_2 & Mobile centrifuge & $11 / 12 / 2012-22 / 01 / 2013$ & Base flow & 41.6 & ND & 12 \\
\hline & ARV_3 & Mobile centrifuge & $22 / 01 / 2013-19 / 02 / 2013$ & Base flow & 101 & 70 & 7 \\
\hline & $\mathrm{ARV} 44$ & Mobile centrifuge & $27 / 03 / 2013-16 / 04 / 2013$ & Base flow & 40.8 & 10 & 12 \\
\hline & ARV_5 & Particle trap & $16 / 05 / 2013-05 / 06 / 2013$ & Base flow & 71.1 & 90 & ND \\
\hline & ARV_6 & Particle trap & 19/06/2013-30/07/2013 & Base flow & 76.4 & 169 & 28 \\
\hline & ARV_7 & Particle trap & $30 / 07 / 2013-26 / 08 / 2013$ & Flood & 62.7 & 343 & 50 \\
\hline & ARV_8 & Particle trap & $26 / 08 / 2013-24 / 09 / 2013$ & Flood & 92.2 & 296 & 28 \\
\hline & ARV_9 & Particle trap & $09 / 03 / 2011$ & Base flow & 122 & 101 & ND \\
\hline & ARV_10 & Particle trap & $20 / 01 / 2012$ & Flood & 114 & 680 & ND \\
\hline \multirow[t]{11}{*}{ Bourbre } & BOU_1 & Mobile centrifuge & $05 / 03 / 2012-30 / 03 / 2012$ & Flood & 22.3 & 205 & 21 \\
\hline & BOU_2 & Mobile centrifuge & $05 / 03 / 2012-30 / 03 / 2012$ & Flood & 16.9 & ND & 15 \\
\hline & BOU_3 & Mobile centrifuge & $30 / 03 / 2012-07 / 05 / 2012$ & Flood & 30.8 & ND & 9 \\
\hline & BOU_4 & Particle trap & $30 / 03 / 2012-07 / 05 / 2012$ & Base flow & 5.96 & 164 & ND \\
\hline & BOU_5 & Particle trap & $15 / 03 / 2013-11 / 04 / 2013$ & Base flow & 5.96 & 164 & ND \\
\hline & BOU_6 & Particle trap & $11 / 04 / 2013-06 / 05 / 2013$ & Flood & 9.65 & 161 & ND \\
\hline & BOU_7 & Particle trap & 01/07/2013-25/07/2013 & Flood & 9.65 & 161 & ND \\
\hline & BOU_8 & Particle trap & $25 / 07 / 2013-28 / 08 / 2013$ & Flood & 13.7 & 104 & 20 \\
\hline & BOU_9 & Particle trap & $11 / 11 / 2012$ & Flood & 15.7 & 159 & 24 \\
\hline & BOU_10 & Particle trap & $02 / 01 / 2012$ & Base flow & 5.7 & 64 & 19 \\
\hline & BOU_11 & Particle trap & $27 / 11 / 2012$ & Flood & 5.55 & 134 & 3 \\
\hline \multirow[t]{15}{*}{ Fier } & FIE_1 & Particle trap & $05 / 03 / 2014-15 / 04 / 2014$ & Base flow & 48.1 & 2.0 & 26 \\
\hline & FIE_2 & Particle trap & $15 / 04 / 2014-20 / 05 / 2014$ & Base flow & 40.8 & 13 & 17 \\
\hline & FIE_3 & Particle trap & $20 / 05 / 2014-25 / 06 / 2014$ & Base flow & 25.5 & 21 & 20 \\
\hline & FIE_4 & Particle trap & $25 / 06 / 2014-29 / 07 / 2014$ & Flood & 52.4 & 28 & 22 \\
\hline & FIE_5 & Particle trap & $29 / 07 / 2014-25 / 08 / 2014$ & Flood & 49.2 & 7.0 & 24 \\
\hline & FIE_6 & Particle trap & $25 / 08 / 2014-18 / 09 / 2014$ & Base flow & 17.5 & 50 & 12 \\
\hline & FIE_7 & Particle trap & $18 / 09 / 2014-20 / 10 / 2014$ & Base flow & 10.3 & 20 & 10 \\
\hline & FIE_8 & Particle trap & $20 / 10 / 2014-25 / 11 / 2014$ & Flood & 31.8 & 34 & 37 \\
\hline & FIE_9 & Particle trap & $25 / 11 / 2014-20 / 01 / 2015$ & Base flow & 18.9 & 31 & 26 \\
\hline & FIE_10 & Particle trap & $18 / 02 / 2015-18 / 03 / 2015$ & Flood & 53.9 & 351 & 43 \\
\hline & FIE_11 & Particle trap & $18 / 03 / 2015-20 / 04 / 2015$ & Flood & 66.5 & 510 & 65 \\
\hline & FIE_12 & Particle trap & 01/09/2015-28/09/2015 & Flood & 26.7 & 232 & 32 \\
\hline & FIE_13 & Particle trap & $28 / 10 / 2015-23 / 11 / 2015$ & Flood & 17.1 & 167 & 37 \\
\hline & FIE_14 & Particle trap & $21 / 12 / 2015-19 / 01 / 2016$ & Flood & 61.9 & 154 & 43 \\
\hline & FIE_15 & Particle trap & $19 / 01 / 2016-18 / 02 / 2016$ & Flood & 72 & 136 & 47 \\
\hline Guiers & GUI_1 & Mobile centrifuge & 05/04/2012-27/04/2012 & Base flow & 20 & 8.4 & ND \\
\hline
\end{tabular}


Table 2 (continued)

\begin{tabular}{|c|c|c|c|c|c|c|c|}
\hline River & Sample & $\begin{array}{l}\text { SPM sampling } \\
\text { method }\end{array}$ & $\begin{array}{l}\text { Date/period } \\
\text { of sampling }\end{array}$ & $\begin{array}{l}\text { Hydrological } \\
\text { condition }\end{array}$ & $\begin{array}{l}\text { Mean discharge } \\
\left(\mathrm{m}^{3} \mathrm{~s}^{-1}\right)\end{array}$ & $\begin{array}{l}\text { Mean SPM } \\
\text { concentration } \\
\left(\mathrm{mg} \mathrm{L}^{-1}\right)\end{array}$ & $\begin{array}{l}\text { Particle size } \\
\text { D50 }(\mu \mathrm{m})\end{array}$ \\
\hline \multirow{28}{*}{$\begin{array}{l}\text { Rhône at } \\
\text { Jons }\end{array}$} & GUI_2 & Mobile centrifuge & 05/04/2012-27/04/2012 & Base flow & 42.7 & ND & ND \\
\hline & GUI_3 & Particle trap & $11 / 05 / 2012-25 / 05 / 2012$ & Flood & 32 & 48 & ND \\
\hline & GUI_4 & Particle trap & $11 / 05 / 2012-25 / 05 / 2012$ & Flood & 32 & 48 & ND \\
\hline & GUI_5 & Particle trap & 19/06/2012-19/07/2012 & Flood & 30.4 & 57 & ND \\
\hline & GUI_6 & Particle trap & $05 / 04 / 2012$ & Flood & 30.4 & 57 & ND \\
\hline & GUI_7 & Particle trap & $27 / 04 / 2012$ & Base flow & 2.83 & 9.0 & ND \\
\hline & GUI_8 & Mobile centrifuge & $10 / 12 / 2018$ & Flood & 109 & 119 & 17 \\
\hline & GUI_9 & Mobile centrifuge & $11 / 12 / 2018$ & Flood & 35 & 19 & 20 \\
\hline & GUI_10 & Manual sampling & $15 / 03 / 2019$ & Base flow & 15 & 264 & 18 \\
\hline & GUI_11 & Mobile centrifuge & $04 / 04 / 2019$ & Flood & 32 & 18 & 18 \\
\hline & GUI_12 & Mobile centrifuge & $20 / 05 / 2019$ & Flood & 216 & 259 & 9 \\
\hline & GUI_13 & Manual sampling & $13 / 06 / 2019$ & Flood & 32 & 269 & 17 \\
\hline & JON_1 & Mobile centrifuge & 08/06/2012-10/06/2012 & Flood & 1825 & 130 & 9 \\
\hline & JON_6 & Mobile centrifuge & $14 / 06 / 2012-15 / 06 / 2012$ & Dam flushing & 1330 & 662 & 11 \\
\hline & JON_8 & Mobile centrifuge & $22 / 05 / 2012-05 / 06 / 2012$ & Dam flushing & 1085 & 336 & 13 \\
\hline & JON_15 & Mobile centrifuge & $11 / 06 / 2012-14 / 06 / 2012$ & Flood & 1975 & 283 & 7 \\
\hline & JON_16 & Automatic sampler & 20/06/2012-03/07/2012 & Dam flushing & 804 & 163 & 9 \\
\hline & JON_17 & Automatic sampler & 03/07/2012-17/07/2012 & Dam flushing & 1290 & 507 & 12 \\
\hline & JON_18 & Particle trap & $17 / 07 / 2012-01 / 08 / 2012$ & Flood & 641 & 30 & 60 \\
\hline & JON_21 & Particle trap & 01/08/2012-14/08/2012 & Dam flushing & 1125 & 510 & 45 \\
\hline & JON_23 & Particle trap & $14 / 08 / 2012-28 / 08 / 2012$ & Flood & 740 & 62 & 17 \\
\hline & JON_24 & Particle trap & 28/08/2012-11/09/2012 & Base flow & 649 & 39 & 18 \\
\hline & JON_25 & Particle trap & $11 / 09 / 2012-25 / 09 / 2012$ & Base flow & 427 & 17 & 14 \\
\hline & JON_26 & Particle trap & $04 / 12 / 2012-17 / 12 / 2012$ & Base flow & 434 & 13 & 13 \\
\hline & JON_27 & Particle trap & $06 / 01 / 2012$ & Base flow & 397 & 12 & 12 \\
\hline & JON_28 & Particle trap & $13 / 06 / 2012$ & Base flow & 440 & 11 & 13 \\
\hline & JON_29 & Particle trap & $15 / 06 / 2012$ & Base flow & 404 & 9.2 & 13 \\
\hline & JON_30 & Particle trap & $16 / 12 / 2012$ & Flood & 1078 & 82 & 27 \\
\hline
\end{tabular}

analyzer respecting good obscuration rate (typically 15\%). An ultrasonic pretreatment was applied before (30 s) and during the analysis to prevent particle aggregation. The volumetric particle size distribution of the sample was computed using the Fraunhofer optical model (AFNOR 2009b). The median diameters of particle size distribution (D50; in $\mu \mathrm{m}$ ), D10 and D90, were computed from the volumetric particle size distributions with the manufacturer's data processing software. An internal standard sample of sediment (Azergues River) was systematically used to determine the analytical error (relative standard deviation, $n=30$ ) for the D50, D10, and D90 values that were below $3 \%, 4 \%$, and $2 \%$, respectively.

\subsection{Extraction and analysis of major and trace elements}

Total trace and major element concentrations in SPM were analyzed from representative sub-samples (30 mg d.w.) digested in closed Teflon reactors using $1.5 \mathrm{~mL} \mathrm{HCl}$ (12 M, Suprapur), $0.5 \mathrm{~mL} \mathrm{HNO}_{3}$ (14 M, Suprapur), and $2 \mathrm{~mL} \mathrm{HF}$ (22 M, Suprapur). Reactors were kept at $110^{\circ} \mathrm{C}$ in an automatic heating block (SC154 HotBlock, Environmental Express) for $2 \mathrm{~h}$. After complete cooling, the digested solutions were evaporated to dryness. The dry residues were dissolved with $250 \mu \mathrm{L} \mathrm{HNO}_{3}$ (14 M, Suprapur) and $5 \mathrm{~mL}$ of ultrapure water (Elga, Veolia) then heated for $30 \mathrm{~min}$ at $100{ }^{\circ} \mathrm{C}$. Exactly $3.5 \mathrm{~mL}$ of the solution were made up to $10 \mathrm{~mL}$ with $6.5 \mathrm{~mL}$ of ultrapure water (Elga, Veolia) and stored at $4{ }^{\circ} \mathrm{C}$ in the dark until further analysis.

Extraction of acid-soluble elements ( $\mathrm{HCl} 1 \mathrm{M})$ is commonly applied to quantify the element fraction bound to the most reactive phases of SPM or sediment (e.g. Morse and Luther III 1999). The $\mathrm{HCl}$-available fraction was extracted by $\mathrm{HCl}$ (1 M, Suprapur; $12.5 \mathrm{~mL}$ ) from $200 \mathrm{mg} \mathrm{d.w.} \mathrm{of} \mathrm{SPM} \mathrm{continuously}$ agitated for $24 \mathrm{~h}$ in PP tubes (50 mL, Starstedt). Samples were then centrifuged (Heraeus Multifuge, X1R) for $20 \mathrm{~min}$ at 
$3000 \mathrm{rpm}$. Aliquots $(10 \mathrm{~mL})$ of the supernatant were transferred into PP tubes $\left(15 \mathrm{~mL}\right.$, Starstedt) and stored at $4{ }^{\circ} \mathrm{C}$ in the dark until further analysis.

Depending on the instrumental limits of quantification (LQ) and SPM concentrations, 18 major and trace elements (Al, As, $\mathrm{Ba}, \mathrm{Co}, \mathrm{Cr}, \mathrm{Cu}, \mathrm{Fe}, \mathrm{Li}, \mathrm{Mg}, \mathrm{Mn}, \mathrm{Na}, \mathrm{Ni}, \mathrm{P}, \mathrm{Pb}, \mathrm{Sr}, \mathrm{Ti}, \mathrm{V}$, and $\mathrm{Zn}$ ) were analyzed by either ICP-OES (Agilent, 720 Series) or ICPMS (Thermo X7, Series II). The LQ for each element/extraction method were determined according to the standard method NF T 90-210(AFNOR 2009a) and are indicated in Table 3. The determination of LQ consists in the measurement of the target LQ concentration in a matrix similar to the samples $\left(\mathrm{HNO}_{3}\right.$ or $\left.\mathrm{HCl}\right)$, in duplicate over five different days. The target $L Q$ is validated if the mean value and associated standard deviation are within $\pm 60 \%$ of the target LQ value. Blanks and certified reference materials (IAEA-158, marine sediment; LGC-6187, River

Table 3 Element concentrations (means and relative standard deviation) in total and HCl-extracted SPM fractions for the Ain, Arve, Bourbre, Fier, and Guiers Rivers and the Rhône River at Jons station (LQ: limit of quantification; $n$ : number of SPM samples)

\begin{tabular}{|c|c|c|c|c|c|c|c|c|c|c|c|c|c|c|}
\hline & & & $\operatorname{Ain}(n=$ & =9) & Arve ( $n$ & $=12)$ & Bourbr & $\mathrm{e}(n=11)$ & Fier $(n$ & =9) & Guiers & $(n=13)$ & Jons $(n=$ & $=16)$ \\
\hline & & LQ & Mean & RSD (\%) & Mean & RSD (\%) & Mean & $\operatorname{RSD}(\%)$ & Mean & RSD (\%) & Mean & RSD (\%) & Mean & $\operatorname{RSD}(\%)$ \\
\hline \multirow[t]{2}{*}{ [Al] $\left(\mathrm{g} \mathrm{kg}^{-1}\right)$} & Total & 0.01 & 29.2 & 24 & 47.4 & 20 & 31.8 & 15 & 35.6 & 16 & 28.7 & 35 & 55.4 & 21 \\
\hline & $\mathrm{HCl}$ & 0.001 & 1.55 & 26 & 2.56 & 30 & 2.08 & 23 & 2.01 & 20 & 1.29 & 48 & 3.72 & 30 \\
\hline \multirow[t]{2}{*}{ [As] $\left(\mathrm{mg} \mathrm{kg}^{-1}\right)$} & Total & 0.10 & 9.30 & 18 & 14.1 & 38 & 9.21 & 19 & 6.50 & 15 & 7.93 & 34 & 11.8 & 21 \\
\hline & $\mathrm{HCl}$ & 0.01 & 1.55 & 17 & 3.74 & 51 & 2.76 & 21 & 1.10 & 13 & 2.20 & 53 & 3.91 & 40 \\
\hline \multirow[t]{2}{*}[\mathrm{Ba}]{$\left(\mathrm{mg} \mathrm{kg}^{-1}\right)$} & Total & 2.50 & 102 & 19 & 296 & 14 & 203 & 7 & 161 & 15 & 142 & 28 & 292 & 23 \\
\hline & $\mathrm{HCl}$ & 0.62 & 17.2 & 24 & 47.2 & 28 & 54.1 & 21 & 29.8 & 19 & 16.5 & 49 & 36.6 & 21 \\
\hline \multirow[t]{2}{*}[\mathrm{Co}]{$\left(\mathrm{mg} \mathrm{kg}^{-1}\right)$} & Total & 2.50 & 6.53 & 20 & 8.13 & 21 & 8.75 & 18 & 8.17 & 17 & 6.11 & 42 & 10.7 & 18 \\
\hline & $\mathrm{HCl}$ & 1.25 & 2.49 & 14 & 3.69 & 18 & 4.91 & 24 & 3.30 & 17 & 2.38 & 43 & 5.92 & 26 \\
\hline \multirow[t]{2}{*}[\mathrm{Cr}]{$\left(\mathrm{mg} \mathrm{kg}^{-1}\right)$} & Total & 2.50 & 41.4 & 24 & 49.2 & 25 & 53.3 & 11 & 68.3 & 14 & 42.59 & 38 & 57.4 & 13 \\
\hline & $\mathrm{HCl}$ & 0.62 & 4.03 & 22 & 5.13 & 47 & 10.2 & 31 & 7.17 & 9 & 6.67 & 108 & 6.52 & 13 \\
\hline \multirow[t]{2}{*}[\mathrm{Cu}]{$\left(\mathrm{mg} \mathrm{kg}^{-1}\right)$} & Total & 2.50 & 16.6 & 26 & 26.9 & 67 & 40.5 & 26 & 20.7 & 25 & 16.7 & 69 & 23.0 & 25 \\
\hline & $\mathrm{HCl}$ & 1.25 & 10.7 & 29 & 14.2 & 75 & 29.8 & 31 & 12.6 & 26 & 12.7 & 96 & 16.6 & 30 \\
\hline \multirow[t]{2}{*}[\mathrm{Fe}]{$\left(\mathrm{g} \mathrm{kg}^{-1}\right)$} & Total & 0.002 & 17.0 & 23 & 20.4 & 21 & 16.8 & 18 & 18.5 & 15 & 14.3 & 37 & 25.6 & 20 \\
\hline & $\mathrm{HCl}$ & 0.001 & 3.97 & 14 & 6.57 & 24 & 5.31 & 21 & 4.79 & 12 & 3.59 & 42 & 9.57 & 30 \\
\hline \multirow[t]{2}{*}{ [Li] $\left(\mathrm{mg} \mathrm{kg}^{-1}\right)$} & Total & 0.50 & 25.9 & 24 & 33.2 & 23 & 21.8 & 20 & 26.0 & 17 & 24.5 & 48 & 42.7 & 27 \\
\hline & $\mathrm{HCl}$ & 0.06 & 0.76 & 14 & 4.46 & 42 & 1.26 & 16 & 1.92 & 17 & 1.41 & 47 & 6.93 & 38 \\
\hline \multirow[t]{2}{*}[\mathrm{Mg}]{$\left(\mathrm{g} \mathrm{kg}^{-1}\right)$} & Total & 0.01 & 5.19 & 13 & 9.80 & 20 & 4.16 & 14 & 9.61 & 7 & 6.07 & 29 & 11.1 & 17 \\
\hline & $\mathrm{HCl}$ & 0.001 & 2.22 & 20 & 4.13 & 17 & 0.99 & 9 & 3.65 & 11 & 2.52 & 34 & 4.41 & 13 \\
\hline \multirow[t]{2}{*}[\mathrm{Mn}]{$\left(\mathrm{mg} \mathrm{kg}^{-1}\right)$} & Total & 2.50 & 415 & 23 & 470 & 22 & 592 & 20 & 504 & 24 & 420 & 49 & 599 & 18 \\
\hline & $\mathrm{HCl}$ & 6.25 & 342 & 21 & 356 & 25 & 507 & 25 & 419 & 27 & 321 & 49 & 472 & 22 \\
\hline \multirow[t]{2}{*}[\mathrm{Na}]{$\left(\mathrm{mg} \mathrm{kg}^{-1}\right)$} & Total & 2.50 & 1850 & 37 & 13,300 & 32 & 4880 & 11 & 6370 & 25 & 5380 & 29 & 10,000 & 17 \\
\hline & $\mathrm{HCl}$ & 6.25 & 106 & 12 & 78.9 & 54 & 89.4 & 24 & 93.2 & 11 & 68.8 & 38 & 82.6 & 22 \\
\hline \multirow[t]{2}{*}[\mathrm{Ni}]{$\left(\mathrm{mg} \mathrm{kg}^{-1}\right)$} & Total & 2.50 & 22.8 & 24 & 30.4 & 30 & 24.2 & 22 & 42.1 & 16 & 19.3 & 43 & 35.1 & 17 \\
\hline & $\mathrm{HCl}$ & 0.62 & 5.54 & 16 & 9.56 & 40 & 8.43 & 26 & 11.3 & 12 & 6.14 & 48 & 12.3 & 19 \\
\hline \multirow[t]{2}{*}[\mathrm{P}]{$\left(\mathrm{g} \mathrm{kg}^{-1}\right)$} & Total & 0.50 & 0.86 & 31 & 1.11 & 76 & 1.47 & 18 & 0.85 & 20 & 1.01 & 41 & 0.77 & 12 \\
\hline & $\mathrm{HCl}$ & 0.003 & 0.39 & 24 & 0.78 & 68 & 0.93 & 21 & 0.51 & 15 & 0.38 & 64 & 0.58 & 13 \\
\hline \multirow[t]{2}{*}[\mathrm{Pb}]{$\left(\mathrm{mg} \mathrm{kg}^{-1}\right)$} & Total & 0.10 & 19.1 & 21 & 20.3 & 40 & 32.4 & 22 & 14.9 & 17 & 15.9 & 36 & 23.2 & 21 \\
\hline & $\mathrm{HCl}$ & 0.01 & 12.8 & 22 & 11.8 & 28 & 25.8 & 24 & 9.54 & 18 & 11.27 & 47 & 17.8 & 26 \\
\hline \multirow[t]{2}{*}[\mathrm{Sr}]{$\left(\mathrm{mg} \mathrm{kg}^{-1}\right)$} & Total & 2.50 & 175 & 12 & 335 & 15 & 198 & 5 & 336 & 16 & 297 & 31 & 293 & 7 \\
\hline & $\mathrm{HCl}$ & 31.2 & 150 & 18 & 262 & 21 & 145 & 5 & 288 & 20 & 246 & 32 & 245 & 7 \\
\hline \multirow[t]{2}{*}{ [Ti] $\left(\mathrm{g} \mathrm{kg}^{-1}\right)$} & Total & 2.50 & 1720 & 22 & 2320 & 21 & 1600 & 13 & 1990 & 14 & 1396 & 41 & 2580 & 17 \\
\hline & $\mathrm{HCl}$ & 0.001 & 11.2 & 20 & 80.6 & 80 & 18.7 & 16 & 15.6 & 25 & 16.0 & 48 & 123 & 45 \\
\hline \multirow[t]{2}{*}{ [Vi] $\left(\mathrm{mg} \mathrm{kg}^{-1}\right)$} & Total & 5.00 & 51.3 & 26 & 52.8 & 23 & 38.8 & 21 & 52.3 & 19 & 39.2 & 46 & 63.0 & 21 \\
\hline & $\mathrm{HCl}$ & 1.25 & 6.91 & 13 & 5.22 & 20 & 5.61 & 23 & 5.74 & 10 & 5.33 & 45 & 7.03 & 18 \\
\hline \multirow[t]{2}{*}[\mathrm{Zn}]{$\left(\mathrm{mg} \mathrm{kg}^{-1}\right)$} & Total & 2.50 & 81.5 & 30 & 82.7 & 37 & 170 & 24 & 81.3 & 22 & 66.7 & 57 & 97.8 & 21 \\
\hline & $\mathrm{HCl}$ & 12.5 & 44.8 & 50 & 41.7 & 58 & 125 & 31 & 43.6 & 26 & 36.1 & 65 & 60.2 & 25 \\
\hline
\end{tabular}

Means of element concentrations $=$ bold

Relative Standard Deviation $=$ ital 
Sediment) were systematically used to control analytical accuracy and precision. Concentrations of major and trace elements in extraction blanks were systematically below the LQ. According to the element, the accuracy of the total extraction method ranged between 94 and 134\% (SI 1) and results were not corrected for extractions yields. Typical expanded uncertainties (i.e. $95 \%$ confidence intervals) calculated as international standard NF ISO 11352 (2012) were lower than 20\%. Assessment of major and trace element concentrations in the residual fraction of SPM was calculated as the difference between concentrations obtained in the total fraction and $\mathrm{HCl}$-extracted fraction. All trace and major element concentrations inferred from the residual fractions were expressed as a mass of element ( $\mu \mathrm{g}$ or $\mathrm{mg}$ ) related to the total (initial) mass of SPM (d.w.).

\subsection{Data treatment}

\subsubsection{Particle size correction}

Correcting major and trace element concentrations from particle size effect may be necessary because the SPM particle size distribution may not be conservative from the sources to the mixing station, due to deposition, erosion, and grain sorting during transport (Laceby et al. 2017). To implement this correction, we applied the methodology proposed by Gellis and Noé (2013). This method is aimed at estimating the element concentrations in the source SPM characterized by the same particle size distribution as the target SPM. It is based on the correlation of the element concentrations in the source samples against their D50, in order to obtain a particle size correction factor, when necessary. In the present study, if the linear correlation of the major or trace element concentrations (total and residual fractions) versus D50 was significant and had a high degree of correlation (Pearson test, $R>0.7, p<0.05$ ) for a given tributary, a correction factor was applied to the element concentrations in both the total and residual fractions as follows:

$$
C_{i, j}=C_{i, j}^{*}-m_{i, j} \times\left(D 50_{j}-D 50_{\mathrm{ref}}\right)
$$

where $C_{i, j}^{*}$ is the initial major or trace element $(i)$ concentration in a tributary $(j), C_{i, j}$ is the major or trace element concentration after particle size correction, $D 50_{j}$ is the median diameter of the tributary sample, $D 50_{\text {ref }}$ is the mean D50 of target SPM, and $m_{i, j}$ is the slope of the regression line of the element concentrations $i$ versus D50 in the tributary $j$.

\subsubsection{Range test}

To assess major and trace element conservativeness during SPM transport from the five tributaries to the sampling station at the outlet of the Upper Rhône River (Jons), we checked that element concentrations in Jons samples remained within the range of the concentrations obtained in SPM samples of the five tributaries. We used the method used by Gellis and Sanisaca (2018) consisting for each target sample that each tracer must be bracketed by the source samples' tracer concentrations $(<10 \%$ of the minimum and $>10 \%$ of maximum tracer concentration). Major and trace elements which did not meet this condition were removed from data treatment. This range test was performed on total and residual fractions element concentrations after particle size correction.

\subsubsection{Selection of discriminant properties and estimation of the relative contribution of each tributary}

Here, we applied the method first formalized by Collins et al. (1997), following a two-stage procedure. The method involved using the Kruskal-Wallis $H$ test to determine suitable properties for discriminating potential sources. Then, a discriminant factor analysis (DFA) was applied to the parameters previously selected by the Kruskal-Wallis $H$ test. A step-by-step algorithm, based on the minimization of the Wilk's lambda, was used to determine the most restrictive combination of parameters that discriminate the maximum number of sources. Then, a linear mixing model was built with the parameters selected by the DA. This model is based on the resolution of a linear equation system, assuming that the SPM flux at the downstream station is a mixture of SPM contributions from the $S$ considered sources as follows:

$C_{i}=\sum_{j=1}^{S} P_{j} \times C_{i, j}+E$

where $C_{i}$ is the concentration of the fingerprint element $i$ in the target sample (e.g. SPM at the downstream station JON); $P_{j}$ is the proportional SPM contribution of the distinct source $j ; C_{i}$, $j$ is the concentration of the fingerprint element $i$ in SPM from the distinct source $j$; and $E$ is the error accounting for imperfect mixing and ignored sources (e.g. ignored tributaries). This equation assumes that SPM at Jons station are a mix of SPM from the Ain, Arve, Bourbre, Fier, and Guiers tributaries. This hypothesis agrees with the first estimation done by Launay (2014) who showed that for an entire hydrological year, 92\% of all SPM fluxes at Jons station corresponded to SPM inputs from these five tributaries. Here, the weighting coefficients have to match the two following conditions:

$\sum_{j=1}^{S} P_{j}=1$ and $P_{j} \geq 0$

The least squares method (R software, package nnls) was applied in order to minimize the $E$ value:

$E 2=\left\|\sum_{j=1}^{S} P_{j} \times C_{i, j}-C_{i}\right\|^{2}$

\subsubsection{Uncertainties of relative contributions}

Finally, a Monte Carlo approach was used in order to take into account the variability of major and trace element 
concentrations of each source and to quantify the uncertainties of each tributary SPM contribution obtained with the mixing model. A frequentist approach was preferred to a probabilistic approach since Davies et al. (2018) reported that probabilistic was better at dealing with non-conservative tracers. For each JON sample, a total of 1000 linear equation systems were generated by randomly selecting one $C_{i, j}$ value among all the concentrations measured for each tributary. The proportional SPM contribution of each source was expressed as the mean of the 1000 mixing model iterations. After verifying that the distributions of the model outputs are approximately normal (Shapiro-Wilk test), a confidence interval (C.I.) with a 95\% confidence level based on the standard normal distribution obtained from the 1000 iterations of the mixing model was estimated as follows:

C.I. $=\left[m-k \times \frac{s}{\sqrt{n}} ; m+k \times \frac{s}{\sqrt{n}}\right]$

where $m$ and $s$ are the mean and standard deviation of the $n$ iterations $(n=1000)$ and $k$ is equal to 1.96 for a confidence level of $95 \%$.

\subsection{1-D numerical hydro-sedimentary model and simulation}

The Rhône River system was modeled using MAGE, a 1-D numerical hydrodynamic code for unsteady flows, coupled with Adis-TS, an advection-dispersion resolution for solute and suspended sediment transport with deposition and erosion (Andriès et al. 2011; Launay et al. 2019). The flow resistance factors of the multi-reach network were calibrated and tested using measured longitudinal water profiles. Cross-sectional profiles of the major tributaries, such as the Arve and Ain Rivers, are included from their confluence with the Rhône to their nearest water and SPM monitoring station. Other tributaries are simply represented as local inputs.

The eight hydropower schemes located upstream Jons station, and their regulation rules were integrated in the model (Launay et al. 2019). The regulation rules include minimum compensation discharge in the by-passed Rhône River, maximum discharge through the plant and bypass canal, and stage-discharge relation in the reservoir. Theoretical rules like this do not reflect the real fluctuations due to hydropeaking and maintenance during routine operation. Input data include water discharges monitored by the Rhône national company (CNR), FOEN (Swiss Hydrological Services) and Regional Directorate of Environment, Development and Housing (DREAL). The SPM concentrations were also provided for the five investigated tributaries (Arve, Fier, Guiers, Bourbre and Ain Rivers). The SPM concentrations of the Arve and Fier Rivers have been continuously recorded at turbidity stations operated by the OSR since 2012 and 2014, respectively (Thollet et al. 2018). Temporary stations have been operated in the Guiers, Bourbre, and Ain Rivers during limited periods. When SPM measurements were not available as calibrated turbidity records, we used SPM concentrations inferred from discharge-SPM concentration relations (sediment rating curves) estimated by Launay (2014). The 1-D numerical model of the Rhône River was used to decompose the flow hydrographs according to water inputs from the different tributaries. This decomposition process provided the relative contributions of the water flowing at the downstream monitoring station at Jons. The SPM fluxes were equally decomposable. All the details on the 1D hydro-sedimentary model are available in Launay et al. (2019).

For each SPM sampling period on the Rhône at Jons station (Table 2), a simulation over the sampling period was used to decompose the flow hydrograph according to water discharge (Fig. 2a) and the SPM fluxes, accounting for SPM propagation and sediment deposition and erosion. The SPM concentration distributions were considered homogenous, with a mean diameter $d=20 \mu \mathrm{m}$ (Fig. 2b). Calibration of the hydro-sedimentary parameters was performed according to Guertault (2015). During the dam flushing event, the SPM re-suspension from the hydropower scheme reservoirs was calibrated against the SPM records measured downstream of the dams.
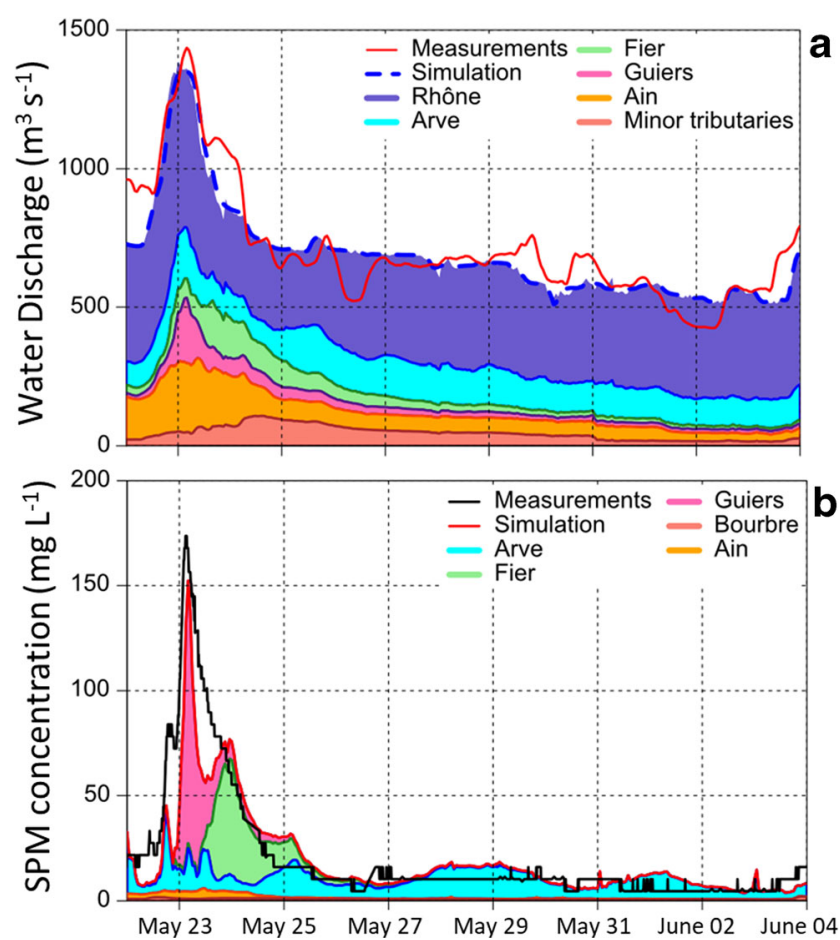

Fig. 2 Example of results from the 1-D hydro-sedimentary numerical model in the upper Rhône River: (a) discharge hydrograph decomposition; (b) SPM concentration decomposition 


\section{Results}

\subsection{Major and trace element concentrations in total and $\mathrm{HCl}$-extracted SPM fractions}

Means and standard deviations of element concentrations in SPM from the five potential sources (Ain, Arve, Bourbre, Fier, and Guiers Rivers) and at the mixing station are detailed in Table 3. The lowest total element mean concentrations were measured on SPM from the Guiers and Ain Rivers. In contrast, the highest total element mean concentrations were obtained on the Arve, the Bourbre, and the Fier Rivers. Total mean concentrations of $\mathrm{Al}, \mathrm{Co}, \mathrm{Fe}, \mathrm{Li}, \mathrm{Mg}, \mathrm{Mn}, \mathrm{Ti}$, and $\mathrm{V}$ were higher in SPM of the Rhône at Jons station than in the five tributaries.

Similar to total element concentrations, the Guiers River displayed the lowest $\mathrm{HCl}$-extracted mean concentrations for several elements. The Arve and Fier Rivers displayed only the one highest $\mathrm{HCl}$-extracted SPM concentration for As and Sr, respectively. In contrast, the Bourbre River displayed the highest $\mathrm{HCl}$-extracted mean SPM concentrations for $\mathrm{Ba}, \mathrm{Cr}$, $\mathrm{Cu}, \mathrm{Mn}, \mathrm{P}, \mathrm{Pb}$, and $\mathrm{Zn}$. On the Rhône at Jons station, $\mathrm{HCl}-$ extracted concentrations of $\mathrm{Al}, \mathrm{As}, \mathrm{Co}, \mathrm{Fe}, \mathrm{Li}, \mathrm{Mg}, \mathrm{Ni}$, Ti, and $\mathrm{V}$ were higher than in the five tributaries.

The mean $\mathrm{HCl}$-extracted element fractions in SPM from the Rhône River and its tributaries represented from $1 \%$ to $86 \%$ of the total element mean concentrations depending on the element (Fig. 3). The HCl-extracted fraction ranged from $1 \%$ to $25 \%$ for $\mathrm{Na}, \mathrm{Ti}, \mathrm{Al}, \mathrm{Li}, \mathrm{V}, \mathrm{Cr}, \mathrm{Ba}$ and As. For Fe, Ni, $\mathrm{Mg}$, and $\mathrm{Co}$, the mean contribution of the $\mathrm{HCl}$-extracted fraction was higher, ranging from $29 \%$ ( $\mathrm{Fe}$ ) to $47 \%$ (Co). Finally, $\mathrm{Zn}, \mathrm{P}, \mathrm{Cu}, \mathrm{Pb}, \mathrm{Mn}$, and $\mathrm{Sr}$ displayed the highest $\mathrm{HCl}$-extracted fractions, ranging from $57 \%$ to $86 \%$.

The PCA analysis on total and HCl-extracted element concentrations (SI 3) suggests that the variabilities of the element concentrations in SPM of the Bourbre, Ain, and Fier Rivers were lower than those observed for the Guiers and Arve River. At this point, this analysis also shows that the raw (without particle size correction and tracer selection) fingerprint of the Bourbre River seems to be distinct from those of the Ain and Guiers Rivers and from those of the Arve and Fier Rivers.

\subsection{Effect of particle size distribution on element concentrations and range test}

When the correlation between element concentrations and particle size distribution was significant (Pearson test, $R>$ $0.7, p<0.05$; SI 2), a correction factor was applied. As an example, plots of element concentrations versus median particle diameter (expressed as the logarithm of D50) are showed for total and residual As concentrations in SPM samples from the Ain River (Fig. 4, Table 4, SI 3). In SPM samples from the Arve River, total concentrations for eight elements $(\mathrm{Co}, \mathrm{Cu}$, $\mathrm{Fe}, \mathrm{Mg}, \mathrm{Mn}, \mathrm{Pb}, \mathrm{V}$, and $\mathrm{Zn}$ ) displayed significant relationships with particle size, and only $\mathrm{Mg}$ and $\mathrm{V}$ concentrations in the residual fraction showed a significant relationship with particle size. In the Bourbre River, total concentrations for 12 elements ( $\mathrm{Al}, \mathrm{As}, \mathrm{Ba}, \mathrm{Co}, \mathrm{Cr}, \mathrm{Fe}, \mathrm{Li}, \mathrm{Mg}, \mathrm{Mn}, \mathrm{Ni}, \mathrm{Ti}$, and V) were significantly correlated with particle size. A significant relationship was also displayed for these elements in the residual fraction except for $\mathrm{Ba}, \mathrm{Mn}, \mathrm{Cu}$, and $\mathrm{Zn}$ (Table 4). For the Fier River, 13 elements (Al, As, Ba, Co, Cr, Cu, Fe, Li, $\mathrm{Mn}, \mathrm{Pb}, \mathrm{Ti}, \mathrm{V}$, and $\mathrm{Zn}$ ) and 11 elements ( $\mathrm{Al}, \mathrm{As}, \mathrm{Cr}, \mathrm{Cu}, \mathrm{Fe}$, $\mathrm{Li}, \mathrm{Mg}, \mathrm{Pb}, \mathrm{Ti}, \mathrm{V}$, and $\mathrm{Zn}$ ) were significantly correlated to particle size in the total and in the residual fractions, respectively. For all these elements and according to the SPM fraction considered (total or residual), a correction factor was applied (Table 4). For the Guiers River, only Li was correlated with particle size in total and residual fractions.

The conservativity test performed for each individual sample at Jons station showed that all elements were within the acceptable range of the corresponding elements concentrations in SPM samples of the five potential sources, except for $\mathrm{Al}, \mathrm{Ba}, \mathrm{Fe}$, and $\mathrm{Li}$ in the total fraction and, for $\mathrm{Al}, \mathrm{Li}$, and $\mathrm{Mg}$ in the residual fraction (Table 4).
Fig. 3 Mean contributions and standard deviation $(n=76)$ of the $\mathrm{HCl}$-extracted fraction of total element concentration in SPM for all stations (Rhône at Jons and 5 main tributaries)

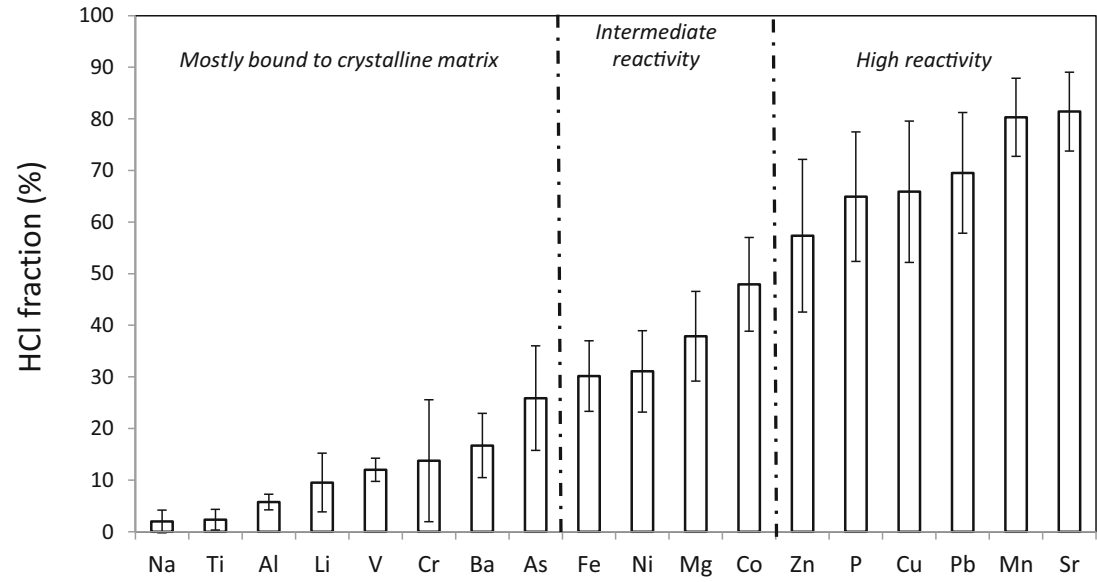




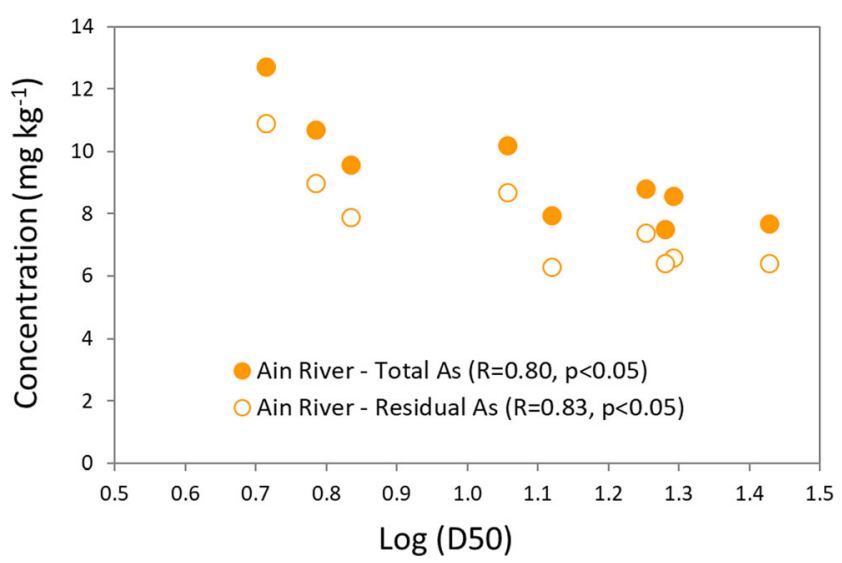

Fig. 4 Relation between As concentrations in total and residual SPM fractions as a function of median particle size (D50) of SPM on the Ain River

\subsection{Discrimination of tracers}

The DFA applied to element concentrations in SPM sources, previously corrected by particle size, indicated that five elements allowed to correctly discriminate the five tributaries. For the total fraction, the selected elements were $\mathrm{Mg}, \mathrm{Ni}, \mathrm{Sr}$, $\mathrm{Mn}$, and As (Table 4). For the residual fraction, $\mathrm{Ba}, \mathrm{Fe}, \mathrm{Ni}$, $\mathrm{Mg}$, and $\mathrm{V}$ were selected as the most discriminating elements for all the samples except JON_16 and JON_17 for which Ba, $\mathrm{Cu}, \mathrm{Ni}$, and $\mathrm{Sr}$ were selected as the most discriminant elements (Table 4).

\subsection{Relative contribution of SPM sources: Fingerprinting and 1-D hydro-sedimentary approaches}

The concentrations of the five elements for the total $(\mathrm{Mg}, \mathrm{Ni}$, $\mathrm{Sr}, \mathrm{Mn}$, and $\mathrm{As}$ ) and residual ( $\mathrm{Ba}, \mathrm{Fe}, \mathrm{Mg}, \mathrm{Ni}$, and $\mathrm{V}$ or $\mathrm{Ba}$, $\mathrm{Cu}, \mathrm{Ni}$, and $\mathrm{Sr}$ ) fractions were used separately in the mixing model to estimate the SPM contributions of each tributary for 15 SPM samples retrieved at Jons station during three contrasting hydrological conditions: base flow, flood, and dam flushing event (Fig. 5).

In general, the relative contributions estimated from element concentrations in the residual fraction are in better agreement with the 1D hydro-sedimentary model than the relative contributions estimated from element concentrations in the total fraction. For four of the five SPM samples retrieved during the dam flushing event, the relative SPM contributions were mainly represented by the Arve River, whether using total or residual element concentrations (Fig. 5a). The contributions of the Arve River were lower for the fingerprinting method using total element concentrations (50\% to $76 \%$ ) than when using element concentrations in the residual fraction (57\% to $88 \%$ ). For JON_21 sample, both fingerprinting methods estimated similar contributions (33 and 37\%) for the Guiers River. However, the fingerprinting model using the total fraction estimated a main contribution of the Ain River (42\%) with a low contribution of the Arve River (8\%). By contrast, the fingerprinting model using the residual fraction estimated higher and similar contributions from the Arve (33\%) and the Bourbre (26\%) Rivers.

For base flow conditions (Fig. 5b), the fingerprinting method using the residual fraction displayed a main contribution (75\% to $81 \%$ ) from the Arve River. These contributions are in agreement with those obtained with the 1D-hydrosedimentary model that estimated that SPM in transit at Jons station were mainly originated from the Arve River (70\% to 91\%). Concerning the fingerprinting method using the total fraction, the Arve River was also determined as the main source of SPM, but with lower contributions, ranging from $44 \%$ to $58 \%$. The lower contributions of the Arve River were counterbalanced by a higher contribution of the Fier River, ranging from $26 \%$ to $33 \%$.

For flood events (Fig. 5c), both fingerprinting approaches using total and residual fractions estimated a lower contribution of the Guiers River for JON_01 sample, with a relative contribution of $5 \%$ and $8 \%$, respectively, in comparison to $49 \%$ according to the 1-D hydro-sedimentary model. The fingerprinting method using the total and residual fractions estimated a higher contribution for the Fier (44\% and 36\%, respectively) and Arve (26\% and $32 \%$, respectively) Rivers. For JON_15 sample, both fingerprinting approaches estimated a main contribution from the Fier River (74\% and 67\%), which is consistent with the contribution of the Fier River (55\%) estimated by the 1D hydro-sedimentary model. However, while the 1Dhydrosedimentary model estimated that the Ain River was the second main source of SPM (28\%), both fingerprinting methods estimated a lower contribution from the Ain River $(<3 \%)$, and a higher contribution from the Arve River (18\% and 30\%). For JON_23 sample, the fingerprinting approach using the residual fraction estimated that the Arve River was the main source of SPM (73\%), which is in agreement with the relative SPM contribution estimated for the Arve River by using the 1D-hydrosedimentary model $(92 \%)$. By using total element concentrations, the fingerprinting method estimated that the contribution of the Arve River was lower (60\%), with a higher contribution from the Fier River (20\%).

For JON_30 sample, the fingerprinting approach using the residual fraction displayed that SPM contributions were equally distributed between the Arve (33\%), Guiers (27\%), Fier (18\%), and Bourbre (17\%) Rivers. The fingerprinting method using the total fraction estimated similar contributions for the Fier River (34\%), Arve River (20\%), and Ain River (30\%). Similar and according to the 1D-hydrosedimentary model, relative contributions were fairly distributed between the Fier (35\%), Ain (33\%), and Guiers (24\%) Rivers. 


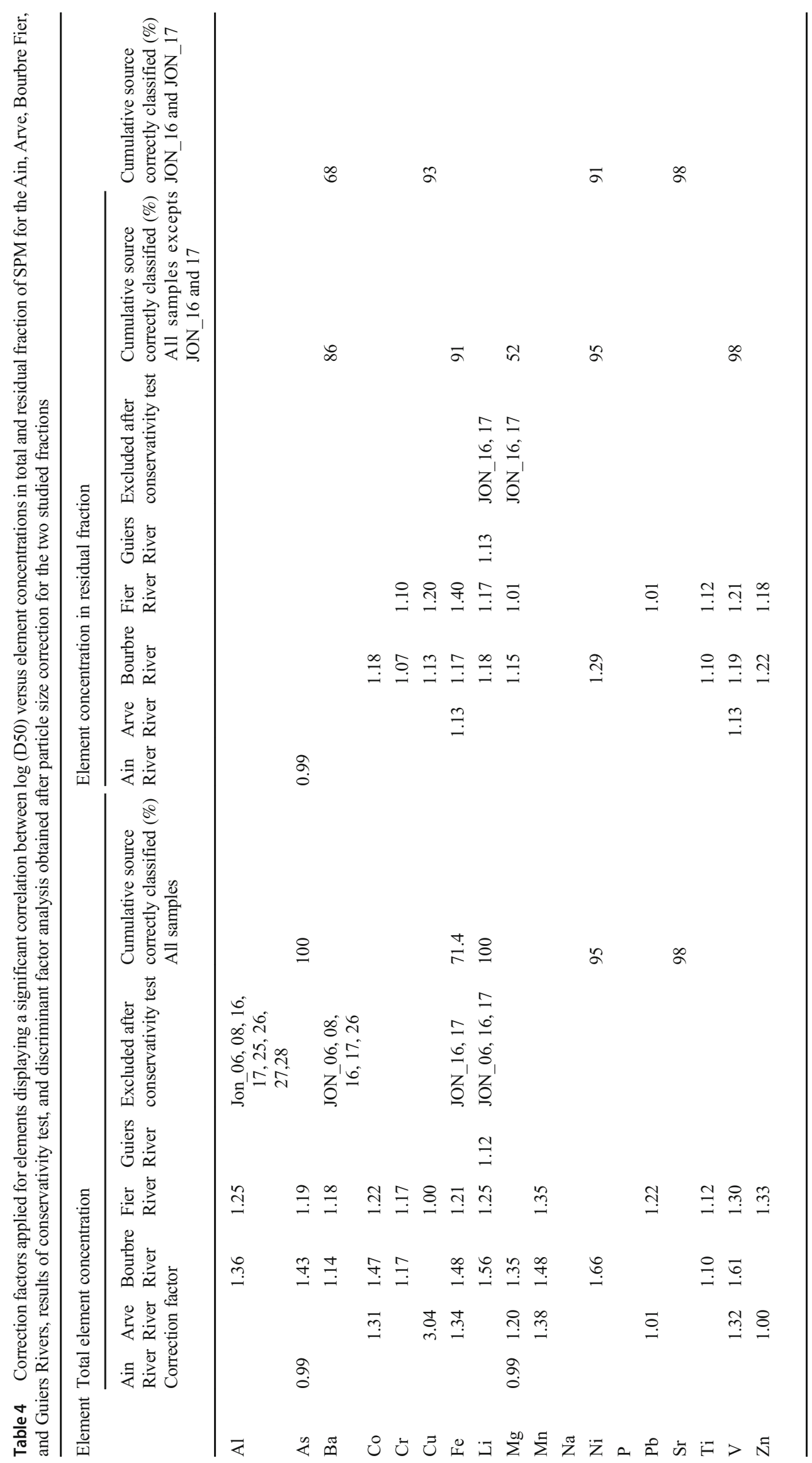




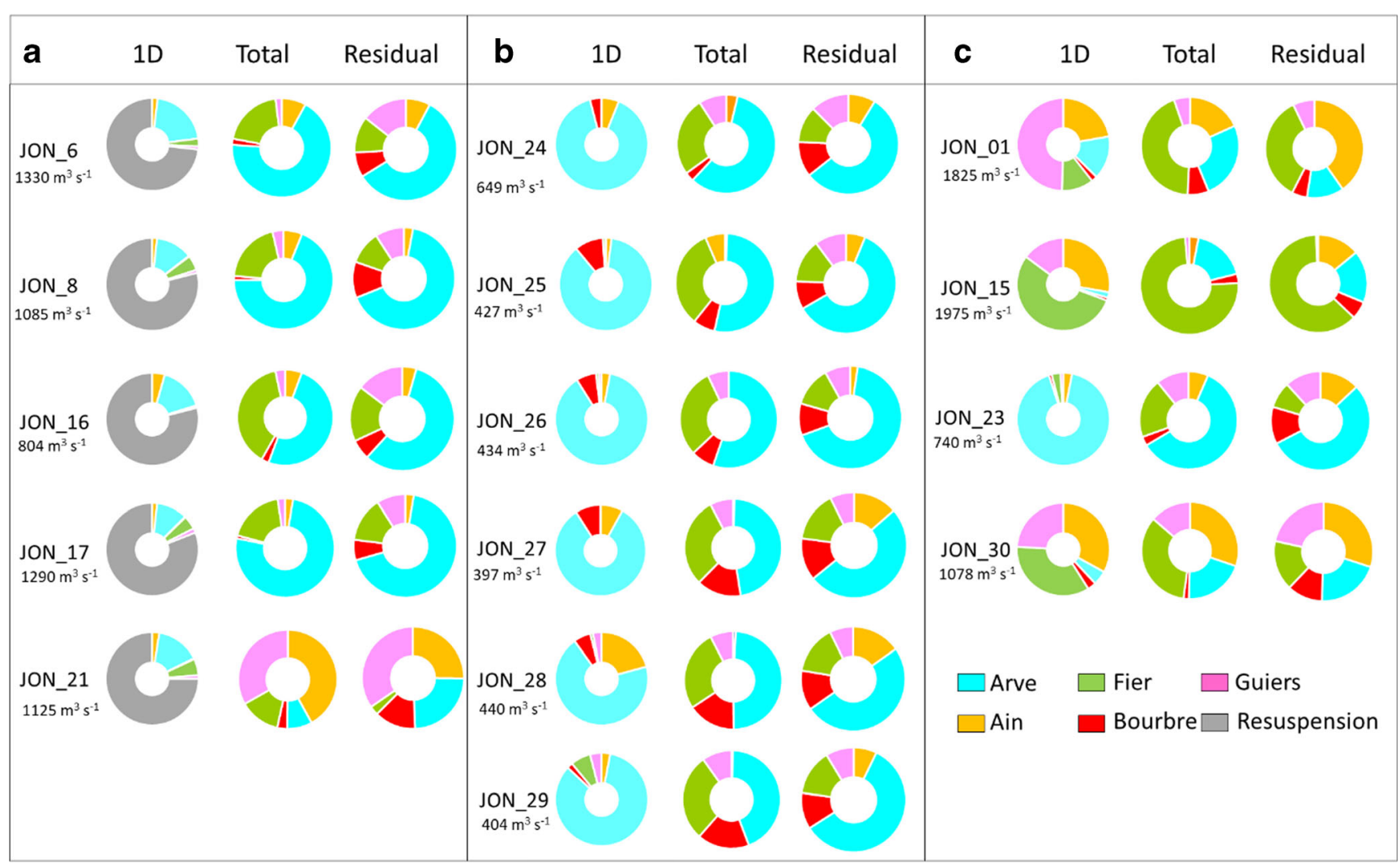

Fig. 5 Relative SPM contribution at Jons station (Rhône River) for SPM collected during dam flushing (a), base flow (b), and flood events (c), estimated by the 1D hydro-sedimentary model and by the fingerprinting approach using element concentrations in the total or in the residual SPM fractions

The results of the Monte Carlo simulations showed that confidence intervals were very low $(<4 \%)$ for each contribution, whether using total or residual fractions (Fig. 6).

\section{Discussion}

\subsection{Relevance of using element concentrations in the residual fraction of SPM to assess sediment sources}

In SPM from the Upper Rhône River, the HCl-extracted fraction represented less than $25 \%$ of the total concentration for $\mathrm{Na}, \mathrm{Ti}, \mathrm{Al}, \mathrm{Li}, \mathrm{V}, \mathrm{Cr}, \mathrm{Ba}$, and As, suggesting that the total concentrations of these elements could be used as conservative tracers, due to their low reactivity. This result could be surprising for $\mathrm{Na}$, since this element is widely recognized to be non-conservative and is often removed from sediment fingerprinting studies, notably in the fine particles $(<63 \mu \mathrm{m})$ of sediment samples (Gholami et al. 2019). As mentioned by Negrel et al. (2015), soil weathering causes a rapid flushing of $\mathrm{Na}$ as dissolved ions. This non-conservative behavior results in the depletion of particulate Na during SPM transport, which is mainly derived from weathering of alumino-silicate phases (dissolution of plagioclase) and evaporites (Negrel et al. 2015). However, through X-ray diffraction (XRD) analysis, Slomberg et al. (2016) reported that mineral composition of SPM sampled at Jons station was mainly represented by five minerals, including the albite (a feldspar plagioclase mineral). If these minerals are still present in SPM at Jons station, this suggests that they are resistant to weathering. This hypothesis is consistent with the study of Aström et al. (1998) who demonstrated that in soils and sediment, elements such as $\mathrm{Na}$ are only to a limited extent extracted in acid aqua regia $\left(1 \mathrm{HCl} / 3 \mathrm{HNO}_{3}, v / v\right)$, so mainly associated with "resistant" minerals such as feldspar. Thus, the low reactivity of $\mathrm{Na}$ (a major constituent of albite mineral) in SPM in Upper Rhône tributaries is consistent since $\mathrm{HCl} 1 \mathrm{M}$ extraction is weaker than an aqua regia extraction.

A second group of elements, $\mathrm{Fe}, \mathrm{Ni}, \mathrm{Mg}$, and $\mathrm{Co}$, displayed an intermediate reactivity, with a $\mathrm{HCl}$-extracted fraction ranging from $29 \%$ to $47 \%$, which is consistent with the results obtained by El Nemr et al. (2006), with HCl-extracted fractions of $43 \%$ for $\mathrm{Fe}$ and $58 \%$ for $\mathrm{Ni}$ in fine sediments of the Suez Gulf. This higher reactivity suggests that attention should be paid before using the total concentrations of these elements to assess sediment sources since there are subjected to change during their transport.

For $\mathrm{Zn}, \mathrm{P}, \mathrm{Cu}, \mathrm{Pb}, \mathrm{Mn}$, or $\mathrm{Sr}$, the use of total concentration as conservative tracers may be even more problematic due to their high reactivity, since the $\mathrm{HCl}$-extracted fraction was 

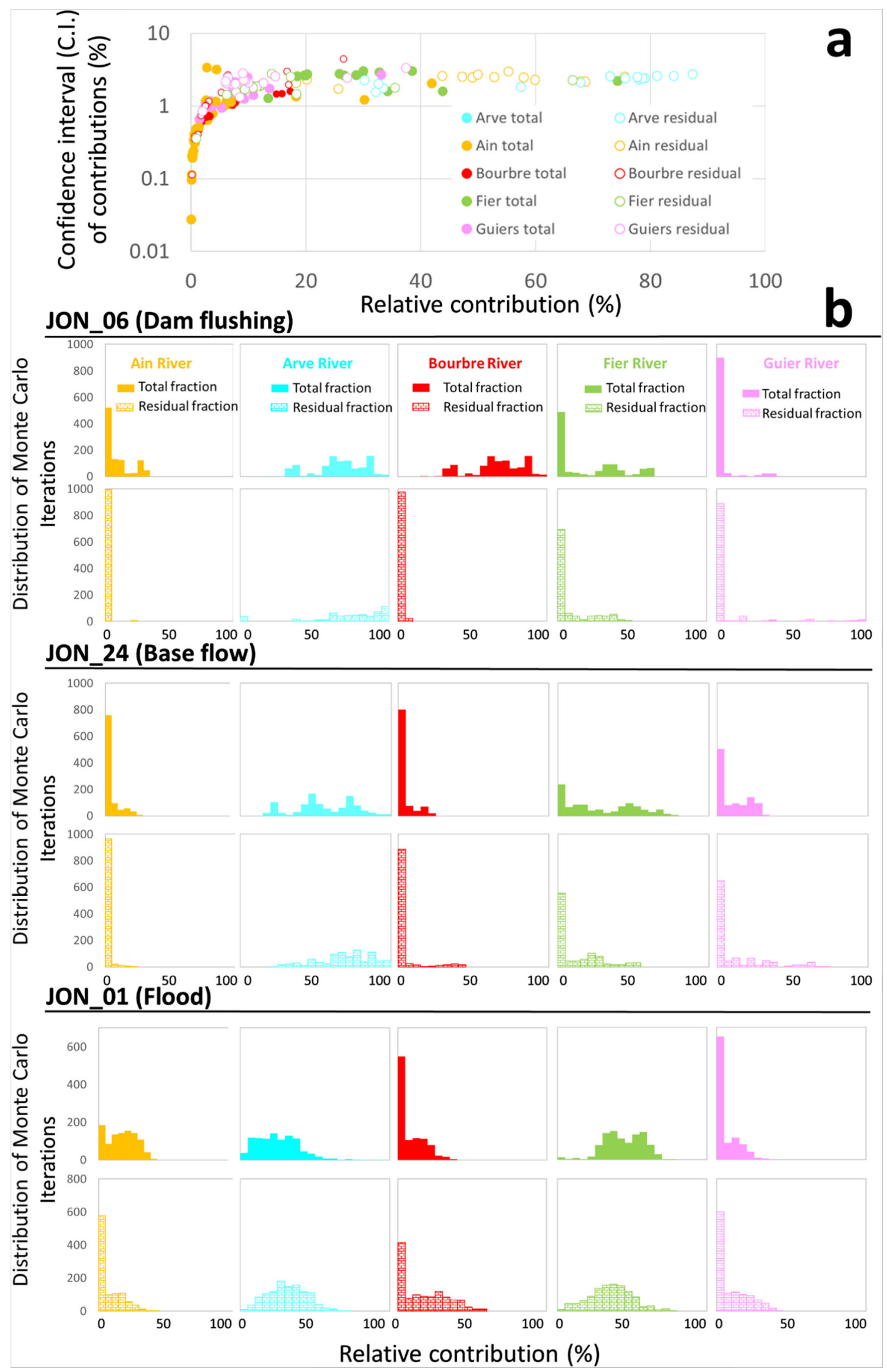
Fig. 6 Confidence interval (C.I.) of each relative SPM contributions (\%) obtained after Monte Carlo simulations by using element concentrations of total and residual SPM fractions (a). Example of Monte Carlo distribution (1000 iterations) for JON_06 (Dam flushing), JON_24 (Base flow) and Jon_01 (Flood) samples (b)

above $50 \%$ (Fig. 3). These results are comparable to those obtained by Dabrin et al. (2014) on SPM from the Garonne River, with contributions of the $\mathrm{HCl}$-extracted fraction representing between $55 \%$ and $78 \%$ of the total $\mathrm{Cu}$ and $\mathrm{Pb}$ concentrations, respectively. Indeed, $\mathrm{Cu}, \mathrm{Pb}$, or $\mathrm{Zn}$ concentrations in SPM are affected by pollution or anthropogenic-based processes, leading to an increase of concentrations in the particulate available fractions (Choi et al. 2012).

Since the tracer selection for SPM source discrimination was only done on a statistical basis (DFA), our results showed that for total element concentrations, four $(\mathrm{Mg}, \mathrm{Ni}, \mathrm{Mn}$, and $\mathrm{Sr}$ ) of the five elements selected by the DFA (Mg, Ni, Sr, Mn, and $\mathrm{As}$ ) were intermediate $(\mathrm{Mg}$ and $\mathrm{Ni}$ ) to highly reactive (Mn and Sr; Fig. 3). This highlights that a common statistical analysis enabled selecting the best combination of elements, without taking their potential reactivity into account. On the contrary, As was mainly bound to the crystalline matrix and was also selected as a fingerprinting tracer. Arsenic is commonly used in fingerprinting approaches (e.g. Theuring et al. 2015), corroborating the idea that total concentrations of As could be used as fingerprinting property.

For the residual fraction, the DFA selected five elements (Ba, $\mathrm{Fe}, \mathrm{Mg}, \mathrm{Ni}, \mathrm{V}$, or $\mathrm{Ba}, \mathrm{Cu}, \mathrm{Ni}$, and $\mathrm{Sr}$ ) including two low reactive elements ( $\mathrm{Ba}$ and $\mathrm{V}$ ), which confirms the relevance of using elements mainly associated with the crystalline matrix of the sediment. The DFA analysis applied on the residual fraction singled out highly-reactive elements such as $\mathrm{Sr}$ and $\mathrm{Cu}$, which were determined as highly reactive elements in the total fraction, with $\mathrm{HCl}$-extracted contributions of $82 \%$ and $65 \%$, respectively. Hence, highly reactive elements that should not be considered relevant for fingerprinting approaches could be considered discriminant fingerprinting properties by using the residual fraction concentrations.

Our approach could be compared to another promising method proposed by Maher et al. (2009) who performed magnetic measurements on untreated and acid-treated samples ( $\mathrm{HCl} 12 \mathrm{M}$ ) of river channel, estuarine, and inner shelf sediments. Despite the measurements of only four magnetic parameters (magnetic susceptibility, anhysteretic remanent magnetization, saturation remanence, and remanence ratios), they showed that the use of acid-treated samples eliminated any influence of post-depositional processes that may modify the initial signature of sediment source. As previously mentioned by Collins et al. (1997), since the fine particle fractions are more geochemically active, they are likely to discriminate sources more robustly. However, this benefit can be counterbalanced because these finer particles are also more subject to transformation and non-conservative behaviors during transport. Most fingerprinting studies use major and trace element concentrations in the total fraction of SPM or sediments after a total digestion (typically by using $\mathrm{HCl}, \mathrm{HNO}_{3}$ and HF or aqua regia; e.g. Le Cloarec et al. 2011; Evrard et al. 2011). Authors of these studies assumed that the total element concentrations in SPM or sediments are conservative during transport, settlement, and remobilization. However, several elements are known to be highly reactive, such as flocculation or precipitation of $\mathrm{Fe}$ and $\mathrm{Mn}$, co-precipitation with $\mathrm{Fe} / \mathrm{Mn}$ oxides of trace metals (e.g. As and V), dissolution, or formation of authigenic iron sulfide in reduced or anoxic conditions (e.g. Morse 2002). Despite their potential non-conservative behaviors, these elements are still used in the literature and in total fraction of our study. Collins et al. (2017) mentioned that despite risks of misinterpretation, some studies have included tracers prone to transformations such as $\mathrm{P}$, as identified by Owens et al. (2000). To assess element concentrations in the most conservative fraction of SPM or sediment, several extraction methods were developed, allowing extracting major and trace elements from different matrices (e.g. exchangeable fraction, carbonates, Fe/Mn oxides, and organic matter) of the sediment (Tessier et al. 1979). Extraction of elements from sediment using $\mathrm{HCl} 1 \mathrm{M}$ is empirically defined as an extraction allowing to assess elements potentially bioavailable (Bryan and Langston 1992). Hydrochloric acid is a strong acid that can solubilize the most reactive phases of the sediment: its reducing properties allow extracting elements from $\mathrm{Fe} / \mathrm{Mn}$ oxides, and it is efficient to decompose labile organic matter and amorphous sulfides (Snape et al. 2004). The concentration of $1 \mathrm{M} \mathrm{HCl}$ is sufficient to buffer the dissolution of carbonates but is low enough to limit the extraction of the residual fraction (Snape et al. 2004). As a result, the difference of element concentrations between total extraction (by using $\mathrm{HCl}, \mathrm{HNO}_{3}$ and $\mathrm{HF}$ ) and $1 \mathrm{M} \mathrm{HCl}$ extraction represents element concentrations in the residual fraction that is mainly primary and secondary minerals of SPM and sediment. This fraction is considered conservative under environmental conditions encountered in the different compartments of the river and avoids any influence of post-depositional processes that may alter the initial signature of SPM.

By using $\mathrm{HCl} 1 \mathrm{M}$, all the particulate reactive carrier phases of elements that could be modified at short or long temporal scale are broken down (Sutherland et al. 2002). This includes adsorbed elements, elements bound to carbonates, to $\mathrm{Fe} / \mathrm{Mn}$ oxide/hydroxides, and to sulfides. The extraction using $\mathrm{HCl}$ $1 \mathrm{M}$ is used to assess acid volatile sulfides (AVS) and simultaneously extractable metals (SEM), conditioning the mobility and toxicity of elements in anoxic sediments (Di Toro et al. 1992). This ability to break down sulfides is interesting to assess sediment sources during flood or dam flushing events, as it overcomes transformed properties of elements coprecipitated with iron and sulfide under anoxic conditions 
(e.g. sediments stored behind dams). Moreover, Agemian and Chau $(1976,1977)$ demonstrated that the use of $0.5 \mathrm{~N} \mathrm{HCl}$ satisfied the essential requirement of minimal dissolution of the silicate detrital lattice and produced the highest contrast between anomalous and background samples. However, Cooper and Morse (1998) reported that $\mathrm{HCl} 1 \mathrm{M}$ was not sufficient to break down $\mathrm{Cu}$ and $\mathrm{Ni}$ sulfide minerals and particulate organic matter. Thus, it would be interesting to improve our methodology, as inferred from the residual fraction of SPM, by adjusting a more appropriate soft extraction allowing to also break down particulate organic matter and/or by adapting soft extractions according to each element. In this way, Dold et al. (2003) demonstrated that $\mathrm{H}_{2} \mathrm{O}_{2}$ extraction (in water bath) was able to dissolve organic matter and supergene $\mathrm{Cu}$-sulfides.

\subsection{SPM source apportionment: Strengths and weaknesses of fingerprinting approach compared to 1D hydro-sedimentary approach}

Five samples of SPM were retrieved at Jons station during the dam flushing event (Jon_6, JON_8, JON_16, JON_17, and JON_21; Table 1, Fig. 5). Both total and residual fractions fingerprinting approaches estimated that SPM from Jons station were mainly constituted by SPM from the Arve River, except for one sample (JON_21). This result is consistent with the literature since the Arve River is known to carry about $500,000 \mathrm{t} \mathrm{year}^{-1}$ of flysch and molasses particles, $50 \%$ of which being trapped behind the Verbois dam (Grimardias et al. 2017). For this event, the hydro-sedimentary model simulated the SPM contribution of each tributary and allowed to estimate that the main input of SPM at Jons station originated from dam flushing re-suspension, with contributions ranging from 69\% (JON_16) to 79\% (JONS_8 and JON_17; Fig. 5a). This may suggest that the relative contribution of resuspended sediment estimated by the 1D-hydrosedimentary model may be attributed to SPM coming from the Arve River. Indeed, by adding the SPM flux from the Arve River and the re-suspended sediment contribution, the 1D hydrosedimentary model estimated that the Arve River contributed about $90-95 \%$ of SPM fluxes at Jons during this event. For JON_21 sample, the relative SPM contributions estimated from the fingerprinting and 1D hydro-sedimentary approaches do not match. This could be explained by the sampling method, since this sample was collected with a particle trap exposed during the first days of the dam flushing event. We can assume that, in the first days of the event, the particle trap integrated re-suspended sediment from different origins and/ or that it induced a bias during SPM sampling in these unusual conditions (Masson et al. 2018). Nonetheless, except for this sample, our results highlighted the complementarity of the fingerprinting and hydro-sedimentary approaches: while the 1-D hydro-sedimentary model allowed to estimate the contribution of sediment re-suspension, the fingerprinting approach using residual fraction allowed to determine its primary origin.

For all the six samples retrieved during base flow conditions (Fig. 5b), the relative contribution of the Arve River obtained using the residual fraction $(75-81 \%)$ was in better agreement with results obtained by the 1D hydro-sedimentary (70-91\%) model than those obtained using the total fraction (44-58\%). Indeed, fingerprinting using the total fraction estimated that about $26 \%$ to $33 \%$ of the contribution was represented by SPM from the Fier River. By contrast, the results for the fingerprinting approach using the residual fraction of SPM displayed relatively high contributions (75-81\%, Fig. 6) from the Arve River. Indeed, in base flow conditions, Rose et al. (2017) demonstrated that SPM were represented by autochthonous SPM mainly made of particulate organic matter and co-precipitated metals. This corroborates the idea that fingerprinting properties in SPM sampled during low flow conditions do not reflect the composition of SPM coming from erosional sources, suggesting using element concentrations in the residual fraction, as it is more representative of eroded material. Thus, according to the fingerprinting approach using element concentrations in the residual fraction, SPM at Jons station mainly originated from the Arve River during base flow discharge. To date, no accurate estimation of SPM flux contributions for a given time for the Upper Rhône basin has been published yet. Based on discharge and SPM measurements at Jons station and tributaries, Launay (2014) estimated that for an entire hydrological year, the Arve River contributed to $45 \%$ of SPM fluxes despite a low water discharge contribution (14\%).

At last, for samples retrieved during flood events (Fig. 5c), the fingerprinting approach using the residual fraction estimated a contribution of the Arve River similar (73\%) to the 1D hydro-sedimentary model (91\%) for JON_23 sample. In comparison, the fingerprinting model using the total element concentrations estimated a contribution of $60 \%$ for the Arve River. For JON_1 sample and according to the 1-D hydrosedimentary model, the period of sampling was characterized by a main SPM input from the Guiers River with a contribution of $49 \%$. However, both fingerprinting approaches and 1D hydro-sedimentary model do not match each other to estimate the SPM contribution from the Guiers River. For JON_15 sample, results obtained for both fingerprinting approaches were in agreement with contributions from the Fier River of $74 \%$ for the approach using total element concentrations and $67 \%$ for the approach using element concentrations in the residual fraction of SPM. This is in agreement with the SPM contribution estimated by the 1-D hydro-sedimentary model with a main contribution of the Fier River (55\%). By contrast, both fingerprinting approaches estimated that the Arve River was the second main input of SPM (18\% and 30\%) with a low contribution of the Ain River $(<3 \%)$, while the 1-D hydro- 
sedimentary model estimated that the second contributor was the Ain River (28\%). Two hypotheses could explain these differences: first, the underestimation of the estimated SPM flux by the fingerprinting models suggests that during these high hydrological conditions, SPM from the Ain River were not well homogenized in the cross-section of the Rhône downstream of the confluence between the Rhône and the Ain Rivers. Indeed, the sampling station at Jons is located in the middle of the Rhône River, upstream of its separation in two main channels (the "Miribel" and "Jonage" channels) and located only at $6 \mathrm{~km}$ downstream the confluence of the Rhône and Ain Rivers (Launay 2014; Fig. 1). We hypothesized that during floods of the Ain River, particles are still flowing on the right side of the Rhône River and are poorly sampled by the particle trap at the Jons station. This hypothesis is corroborated by the study conducted by Bouchez et al. (2010), which showed that lateral mixing downstream confluences in large rivers are at least of several tens of kilometers. The second hypothesis is related to an overestimation of the Arve River input: since this tributary is the main input of SPM through an entire hydrological year (Launay 2014), we could assume that bed sediment is mainly represented by SPM from the Arve River. During high water discharge, a fraction of SPM sampled at Jons station may be represented by bed-sediment remobilization with a composition strongly derived from the Arve River. For JON_30 sample, the 1-D hydro-sedimentary model estimated that SPM contributions were equally distributed between SPM inputs from the Fier (35\%), Ain (33\%), and Guiers (24\%) Rivers. During this high hydrological condition, the estimation of SPM contribution through both fingerprinting approaches was more uncertain. The two fingerprinting approaches estimated a non-negligible contribution from the Guiers River (14\% and $27 \%$ respectively) and from the Fier River ( 34 and 18\%). However, in the same way as for JON_15 sample, both fingerprinting approaches overestimated the Arve River contribution (20\% and 33\% respectively for total and residual fractions). During flood, when SPM contribution is not predominantly represented by one tributary, the fingerprinting approach slightly differed from the 1-D hydro-sedimentary model, probably (i) by overestimating the Arve River contribution due to resuspension of bed sediment (mainly composed by sediment from the Arve River) and (ii) by a sampling method not suitable to take into account SPM inputs from the Ain River.

\section{Conclusion}

Trace and major element concentrations were determined in SPM sampled during contrasting hydrological conditions in the Upper part of the French Rhône River and its main tributaries, the Arve, Ain, Bourbre, Fier, and Guiers Rivers. Using a total $\left(\mathrm{HCl}, \mathrm{HNO}_{3}\right.$, and $\left.\mathrm{HF}\right)$ and a soft extraction $(\mathrm{HCl} 1 \mathrm{M})$ of elements in SPM, we highlighted the potential reactivity of major and trace elements in SPM for a large-sized catchment such as the Upper Rhône hydrosystem. Through the use of a mixing model combined with a Monte Carlo procedure, using total and residual element concentrations, we estimated the SPM contributions of the main tributaries of the Upper Rhône River at Jons station for contrasting hydrological conditions. This methodology is proposed to avoid taking into account the most reactive part of the sediments whose geochemical signature can change during transport. The crossvalidation of the results allowed a critical interpretation of the results obtained by the use of fingerprinting approach. By comparing the mixing model results of both fingerprinting approaches with those of a 1-D numerical hydro-sedimentary model, we showed that it was more relevant to use element concentrations in the residual fraction of SPM to identify SPM sources at large-watershed scale. This study demonstrated that in base flow conditions, SPM fluxes at Jons station were mainly made of SPM originating from the Arve River. We further showed that this fingerprinting approach could discriminate the SPM origin of the sediment re-suspended during dam flushing events and was complementary to the 1-D hydrosedimentary model for such events. A next step will be to validate this geochemical approach by applying it to the entire Rhône watershed and to sediment cores to assess the present and historical relative SPM contributions of the Rhône tributaries and sub-catchments to the Mediterranean Sea.

Supplementary Information The online version contains supplementary material available at https://doi.org/10.1007/s11368-020-02856-0.

Acknowledgments This study was supported by the Rhône Sediment Observatory (OSR), a multi-partners research program partly funded by the Plan Rhône and by the European Regional Development Fund (ERDF). We would like to thank the partner organizations that provided data to the OSR database, especially for this study: CNR (Compagnie Nationale du Rhône), FOEN (Federal Office of the Environment, Switzerland), Grand Lyon urban council, Veolia, DREAL (French hydrological services), and EDF (Electricité de France). We thank our INRAE colleagues Mickaël Lagouy, Josselin Panay, Fabien Thollet, and Lysiane Dherret for their invaluable assistance for SPM sampling, field campaigns, and sample treatment and analyses and Benjamin Renard for his help in the statistical treatment of data.

\section{References}

AFNOR (2009a) NF T 90-210: water quality - protocol for the initial evaluation of the performance of a method in a laboratory, $43 \mathrm{pp}$

AFNOR (2009b) NF ISO 13320: particle size analysis - laser diffraction methods, $51 \mathrm{pp}$

Agemian H, Chau ASY (1976) Evaluation of extraction techniques for the determination of metals in aquatic sediments. Analyst 101(1207):761-767

Agemian H, Chau ASY (1977) A study of different analytical extraction methods for nondetrital heavy metals in aquatic sediments. Arch Environ Contam Toxicol 6(1):69-82 
Andriès E, Le Coz J, Camenen B, Faure JB, Launay M (2011) Impact of dam flushes on bed clogging in a secondary channel of the Rhône River. Proceedings of RCEM (River, Coastal and Estuarine Morphodynamics), Beijing

Antonelli C, Eyrolle F, Rolland B, Provansal M, Sabatier F (2008) Suspended sediment and $137 \mathrm{Cs}$ fluxes during the exceptional December 2003 flood in the Rhone River, Southeast France. Geomorphology 95:350-360

Aström M (1998) Mobility of Al, P and alkali and alkaline earth metals in acid sulphate soils in Finland. Sci Total Environ 215:19-30

Bouchez J, Lajeunesse J, Gaillardet C, France-Lanord P, Dutra M, Maurice L (2010) Turbulent mixing in the Amazon River: the isotopic memory of confluences. Earth Planet Sci Lett 290:37-43

Brown AG, Carpenter RG, Walling DE (2008) Monitoring the fluvial palynomorph load in a lowland temperate catchment and its relationship to suspended sediment and discharge. Hydrobiologia 607: $27-40$

Bryan GW, Langston WJ (1992) Bioavailability, accumulation and effects of heavy metals in sediments with special reference to United Kingdom estuaries: a review. Environ Pollut 76:89-131

Chen F, Fang N, Shi Z (2016) Using biomarkers as fingerprint properties to identify sediment sources in a small catchment. Sci Total Environ 557-558:123-133

Choi KY, Kim SH, Chon HT (2012) Relationship between total concentration and dilute $\mathrm{HCl}$ extraction of heavy metals in sediments of harbors and coastal areas in Korea. Environ Geochem Health 34: 243-250

Collins AL, Walling DE, Leeks GJL (1997) Source type ascription for fluvial suspended sediment based on a quantitative composite fingerprinting technique. Catena 29:1-27

Collins AL, Walling DE (2004) Documenting catchment suspended sediment sources: problems, approaches and prospects. Prog Phys Geogr 28:159-196

Collins AL, Walling DE, Leeks GJL (2005) Storage of fine-grained sediment and associated contaminants within the channels of lowland permeable catchments in the UK. IAHS-AISH Publ 291:259-268

Collins AL, Zhang Y, Walling DE, Grenfell SE, Smith P, Grischeff J, Locke A, Sweetapple A, Brogden D (2012) Quantifying finegrained sediment sources in the river axe catchment, Southwest England: application of a Monte Carlo numerical modelling framework incorporating local and genetic algorithm optimisation. Hydrol Process 26:1962-1983

Collins AL, Pulley S, Foster IDL, Gellis A, Porto P, Horowitz AJ (2017) Sediment source fingerprinting as an aid to catchment management: a review of the current state of knowledge and a methodological decision-tree for end-users. J Environ Manag 194:86-108

Cooper DC, Morse JW (1998) Extractability of metal sulfide minerals in acidic solutions: application to environmental studies of trace metal contamination within anoxic sediments. Environ Sci Technol 32(8): 1076-1078

Dabrin A, Schäfer J, Blanc G, Strady E, Masson M, Bossy C, Castelle S, Girardot N, Coynel A (2009) Improving estuarine net flux estimates for dissolved cadmium export at the annual timescale: application to the Gironde estuary. Estuar Coast Shelf S 84:429-439

Dabrin A, Schäfer J, Bertrand O, Masson M, Blanc G (2014) Origin of suspended matter and sediment inferred from the residual metal fraction: application to the Marennes Oleron Bay, France. Cont Shelf Res 72:119-130

Davies J, Olley J, Hawker, D McBroom J (2018) Application of the Bayesian approach to sediment fingerprinting and source attribution. Hydrol Process 32:3978-3995

Di Toro DM, Mahony JD, Hansen DJ, Scott KJ, Carlson AR, Ankley GT (1992) Acid volatile sulfide predicts the acute toxicity of cadmium and nickel in sediments. Environ Sci Technol 26:96-101
Dold B (2003) Speciation of the most soluble phases in a sequential extraction procedure adapted for geochemical studies of copper sulfide mine waste. J Geochem Explor 80(1):55-68

El Nemr A, Khaled A, El Sikaily A (2006) Distribution and statistical analysis of leachable and total heavy metals in the sediments of the Suez Gulf. Environ Monit Assess 118:89-112

Evrard O, Navratil O, Ayrault S, Ahmadi M, Nemery J, Legout C, Lefèvre I, Poirel A, Bonte P, Esteves M (2011) Combining suspended sediment monitoring and fingerprinting to determine the spatial origin of fine sediment in a mountainous river catchment. Earth Surf Process Landf 36:1072-1089

Franks SW, Rowan JS (2000)Multi-parameter fingerprinting of sediment sources: uncertainty estimation and tracer selection. Computational methods in water resources, volume 2, computational methods, surface water systems and hydrology pp. 1067-1074

Fryirs K (2013) (Dis)connectivity in catchment sediment cascades: a fresh look at the sediment delivery problem. Earth Surf Process Landf 38:30-46

Fu B, Newham LTH, Field JB (2008) Influence of particle size on geochemical suspended sediment tracing in Australia. IAHS-AISH Publ 325:23-30

Gellis A, Noe G (2013) Sediment source analysis in the Linganore Creek watershed, Maryland, USA, using the sediment fingerprinting approach: 2008 to 2010. J Soils Sediments 13:17351753

Gellis AC, Walling DE (2011) Sediment source fingerprinting (Tracing) and sediment budgets as tools in targeting river and watershed restoration programs. In: Geoph Monog Series, pp 263-291

Gellis AC, Sanisaca LG (2018) Sediment fingerprinting to delineate sources of sediment in the agricultural and forested Smith Creek Watershed, Virginia, USA. J Am Water Resour Assoc 54(6): $1197-1221$

Guertault L (2015) Evaluation of the hydro-sedimentary processes of an elongated reservoir: application to the Génissiat reservoir on the upper Rhône. University of Lyon, Lyon

Gholami H, Takhtinajad EJ, Collins AL, Fathabadi A (2019) Monte Carlo fingerprinting of the terrestrial sources of different particle size fractions of coastal sediment deposits using geochemical tracers: some lessons for the user community. Environ Sci Pollut Res 26: 13560-13579

Grimardias D, Guillard J, Cattanéo F (2017) Drawdown flushing of a hydroelectric reservoir on the Rhône River: impacts on the fish community and implications for the sediment management. J Environ Manag 197:239-249

Heemken OP, Stachel B, Theobald N, Wenclawiak BW (2000) Temporal variability of organic micropollutants in suspended particulate matter of the River Elbe at Hamburg and the River Mulde at Dessau, Germany. Arch Environ Contam Toxicol 38:11-31

House WA, Warwick MS (1999) Interactions of phosphorus with sediments in the River Swale, Yorkshire, UK. Hydrol Process 13:11031115

Kimoto A, Nearing MA, Zhang XC, Powell DM (2006) Applicability of rare earth element oxides as a sediment tracer for coarse-textured soils. Catena 65:214-221

Koiter AJ, Owens PN, Petticrew EL, Lobb DA (2013) The behavioural characteristics of sediment properties and their implications for sediment fingerprinting as an approach for identifying sediment sources in river basins. Earth Sci Rev 125:24-42

Laceby JP, Evrard O, Smith HG, Blake WH, Olley JM, Minella JPG, Owens PN (2017) The challenges and opportunities of addressing particle size effects in sediment source fingerprinting: a review. Earth-Sci Rev 169:85-103

Launay M (2014) Fluxes of suspended particulate matters, particulate mercury and PCBs in the Rhône river from Lake Geneva to the Mediterranean. University of Lyon, Lyon 
Launay M, Le Coz J, Camenen B, Walter C, Angot H, Dramais G, Faure JB, Coquery M (2015) Calibrating pollutant dispersion in 1-D hydraulic models of river networks. J Hydro Environ Res 9:120-132

Launay M, Dugué V, Faure JB, Coquery M, Camenen B, Le Coz J (2019) Numerical modelling of the suspended particulate matter dynamics in a regulated river network. Sci Total Environ 665:591-605

Le Cloarec MF, Bonte PH, Lestel L, Lefèvre I, Ayrault S (2011) Sedimentary record of metal contamination in the Seine River during the last century. Phys Chem Earth 36:515-529

Legout C, Poulenard J, Nemery J, Navratil O, Grangeon T, Evrard O, Esteves M (2013) Quantifying suspended sediment sources during runoff events in headwater catchments using spectrocolorimetry. J Soils Sediments 13:1478-1492

Lepage H, Launay M, Le Coz J, Angot H, Miege C, Gairoard S, Radakovitch O, Coquery M (2020) Impact of dam flushing operations on sediment dynamics and quality in the upper Rhône River. France J Environ Manage 255:109886. https://doi.org/10.1016/j. jenvman.2019.109886

Maher BA, Watkins SJ, Brunskill G, Alexander J, Fielding CR (2009) Sediment provenance in a tropical fluvial and marine context by magnetic 'fingerprinting' of transportable sand fractions. Sedimentology 56:841-861

Maleki FS, Khan AA (2016)1-D coupled non-equilibrium sediment transport modeling for unsteady flows in the discontinuous Galerkin framework. J Hydrodyn 28:534-543

Martínez-Carreras N, Krein A, Gallart F, Iffly JF, Pfister L, Hoffmann L, Owens PN (2010) Assessment of different colour parameters for discriminating potential suspended sediment sources and provenance: a multi-scale study in Luxembourg. Geomorphology 118: $118-129$

Masson M, Angot H, Le Bescond C, Launay M, Dabrin A, Miège C, Le Coz J, Coquery M (2018) Sampling of suspended particulate matter using particle traps in the Rhône River: relevance and representativeness for the monitoring of contaminants. Sci Total Environ 637 638:538-549

Morse JW (2002) Sedimentary geochemistry of the carbonate and sulphide systems and their potential influence on toxic metal bioavailability. In: Gianguzza A, Pelizzetti E, Sammartani S (eds) Chemistry of Marine Water and Sediments. Springer-Verlag, Berlin, pp 164 189

Morse JW, Luther III GW (1999) Chemical influences on trace metalsulfide interactions in anoxic sediments. Geochim Cosmochim Acta 63:3373-3378

Motha JA, Wallbrink PJ, Hairsine PB, Grayson RB (2002) Tracer properties of eroded sediment and source material. Hydrol Process 16: 1983-2000

Mukundan R, Radcliffe DE, Ritchie JC, Risse LM, McKinley RA (2010) Sediment fingerprinting to determine the source of suspended sediment in a southern Piedmont stream. J Environ Qual 39:1328-1337

Navratil O, Evrard O, Esteves M, Ayrault S, Lefèvre I, Legout C, Reyss JL, Gratiot N, Nemery J, Mathys N, Poirel A, Bonté P (2012)Corederived historical records of suspended sediment origin in a mesoscale mountainous catchment: the River Bléone, Frenc Alps. J Soils Sediments 12:1463-1478

Negrel P, Sadeghi M, Ladenberger A, Reimann C, Birke M (2015) Geochemical fingerprinting and source discrimination of agricultural soils at continental scale. Chem Geol 396:1-15

Ollivier P, Radakovitch O, Hamelin B (2011) Major and trace element partition and fluxes in the Rhône River. Chem Geol 285:15-31

Owens PN, Walling DE, Leeks GJL (2000) Tracing fluvial suspended sediment sources in the catchment of the River Tweed, Scotland, using composite fingerprints and a numerical mixing model. In: Foster IDL (ed) Tracers in geomorphology. Wiley, Chichester, pp 291-308
Palazón L, Latorre B, Gaspar L, Blake WH, Smith HG, Navas A (2015) Comparing catchment sediment fingerprinting procedures using an auto-evaluation approach with virtual sample mixtures. Sci Total Environ 532:456-466

Poulier G, Launay M, Le Bescond C, Thollet F, Coquery M, Le Coz J (2019) Combining flux monitoring and data reconstruction to establish annual budgets of suspended particulate matter, mercury and PCB in the Rhône River from Lake Geneva to the Mediterranean Sea. Sci Total Environ 658:457-473

Rose LA, Karwan DL, Aufdenkampe AK (2017) Sediment fingerprinting suggests differential suspended particulate matter formation and transport processes across hydrologic regimes. J Geophys Res Biogeosci 123:1213-1229

Rotman R, Naylor L, McDonnell R, MacNiocaill C (2008) Sediment transport on the Freiston Shore managed realignment site: an investigation using environmental magnetism. Geomorphology 100:241255

Slomberg D, Ollivier P, Radakovitch O, Baran N, Sani-Kast N, Miche H, Borschneck D, Grauby O, Bruchet A, Scheringer M, Labille J (2016) Characterisation of suspended particulate matter in the Rhône River: insights into analogue selection. Environ Chem 13: 804-815

Smith HG, Blake WH (2014) Sediment fingerprinting in agricultural catchments: a critical re-examination of source discrimination and data corrections. Geomorphology 204:177-191

Snape I, Scouller RC, Stark SC, Stark J, Riddle MJ, Gore DB (2004) Characterisation of the dilute $\mathrm{HCl}$ extraction method for the identification of metal contamination in Antarctic marine sediments. Chemosphere 57:491-504

Sutherland RA (2002) Comparison between non-residual Al, $\mathrm{Co}, \mathrm{Cu}, \mathrm{Fe}$, $\mathrm{Mn}, \mathrm{Ni}, \mathrm{Pb}$ and $\mathrm{Zn}$ released by a three-step sequential extraction procedure and a dilute hydrochloric acid leach for soil and road deposited sediment. J Appl Geochem 17(4):353-365

Tessier A, Campbell PGC, Bisson M (1979) Sequential extraction procedure for the speciation of particulate trace metals. Anal Chem 51: 844-851

Theuring P, Collins AL, Rode M (2015) Source identification of finegrained suspended sediment in the Kharaa River basin, northern Mongolia. Sci Total Environ 526:77-87

Thollet F, Le Bescond C, Lagouy M, Gruat A, Grisot G, Le Coz J, Coquery M, Lepage H, Gairoard S, Gattacceca JC, Ambrosi JP, Radakovitch O (2018) Observatoire des Sédiments du Rhône, Irstea https://doi.org/10.17180/OBS.OSR

Vale SS, Fuller IC, Procter JN, Basher LR, Smith IE (2016) Application of a confluence-based sediment-fingerprinting approach to a dynamic sedimentary catchment, New Zealand. Hydrol Process 30:812829

Walling DE (2013) The evolution of sediment source fingerprinting investigations in fluvial systems. J Soils Sediments 13:1658-1675

Walling DE, Owens PN, Leeks GJL (1999) Fingerprinting suspended sediment sources in the catchment of the river Ouse, Yorkshire, UK. Hydrol Process 13:955-975

Wilkinson SN, Hancock GJ, Bartley R, Hawdon AA, Keen RJ (2013) Using sediment tracing to assess processes and spatial patterns of erosion in grazed rangelands, Burdekin River basin, Australia. Agric Ecosyst Environ 180:90-102

Zebracki M, Eyrolle-Boyer F, Evrard O, Claval D, Mourier B, Gairoard S, Cagnat X, Antonelli C (2015) Tracing the origin of suspended sediment in a large Mediterranean river by combining continuous river monitoring and measurement of artificial and natural radionuclides. Sci Total Environ 502:122-132

Publisher's note Springer Nature remains neutral with regard to jurisdictional claims in published maps and institutional affiliations. 